Alma Mater Studiorum - Università di Bologna DEPARTMENT OF ECONOMICS

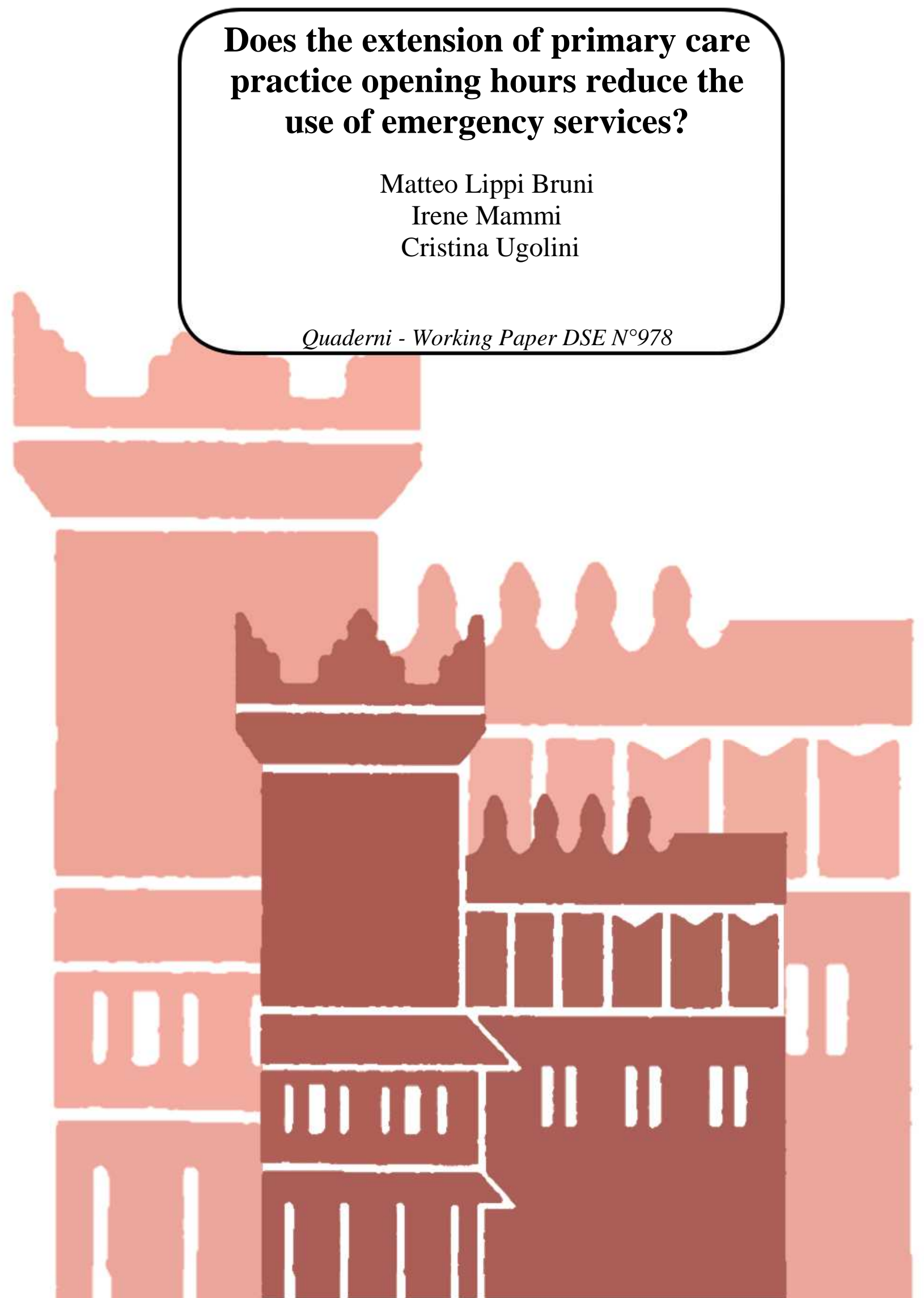




\title{
Does the extension of primary care practice opening hours reduce the use of emergency services?
}

\author{
Matteo Lippi Bruni, Irene Mammi* and Cristina Ugolini \\ Department of Economics, University of Bologna
}

13 November 2014

\begin{abstract}
Over-crowding in Emergency Departments (EDs) generates potential inefficiencies. Using regional administrative data, we investigate the impact of an increase in the accessibility of primary care on ED visits in Italy. We test whether extending practice opening hours up to 12 hours/day reduces inappropriate ED visits. We estimate count data models, considering different measures for ED visits recorded at the list level. Since the extension programme is voluntary, we also account for the potential endogeneity of participation, using a two-stage residual inclusion and a GMM approach. Our results show that improving primary care accessibility favours a more appropriate use of EDs.
\end{abstract}

Key words: count data models, emergency services, GMM, health econometrics, primary care, two-stage residual inclusion.

JEL classification: I11, I18, C31

Acknowledgements

The paper is part of the research project "The role of economic incentives in the governance of primary care" financed by the Health Department of Emilia-Romagna, Italy, that also provided the data. The paper greatly benefited from comments by Stephen G. Hall and the participants to the LAGV12 (Aix en Provence), SIE (Italian Economists Association), iHEA 2014 (Dublin) conferences and to the Health Econometrics Workshop 2014 (University of Padua). We are also grateful to Andrea Donatini of the Health Department of Emilia-Romagna for useful suggestions and valuable support throughout the research. The work reflects exclusively authors' opinions and does not involve the above mentioned institution. Other usual disclaimers apply.

*Corresponding author: Irene Mammi, Department of Economics, University of Bologna, Piazza Scaravilli 2, 40126 Bologna, Italy. E-mail: irene.mammi@unibo.it 


\section{Introduction}

Overcrowding in Emergency Departments (EDs) raises well-documented concerns, since high attendance rates result in the inefficient allocation of resources between community and hospital care, and reduce the capacity to provide timely responses to the needs of critical patients (Pines et al., 2011; Flores-Mateo et al., 2012). Besides the resulting delays in treatment, an intensive utilisation of emergency wards also increases pressure on hospital resources, including diagnostic and specialist services. Moreover, in the case of chronic diseases the disruption in the continuity of care may adversely affect health outcomes. All these concerns are especially serious in those cases that do not meet the severity and urgency requirements of ED care, and for which outpatient care settings could be equally as effective.

The share of ED visits deemed to be avoidable is estimated at around 25\% in Canada (Afilalo et al., 2004; Howard et al., 2008), 30\% in European countries such as France (Lang, 1996), Sweden (Hansagi et al., 1987) and Spain (Sempere-Selva et al., 2001) and up to 50\% in Taiwan (Chan et al., 2013). In Italy, Bianco et al. (2003) focus on the urgency criterion and estimate that non-urgent visits to EDs in the Calabria Region amount to $20 \%$ of total visits. In the USA, the estimated rates are lower, ranging from between 5\% and $13 \%$ (McCraig et al., 2006; GAO, 2009). Figures vary depending not only on the institutional circumstances, but also on the alternative criteria used to identify patients that could be treated in a primary care setting (Durand et al., 2011). One frequently-held view is that ED attenders requiring urgent treatment are considered appropriate users of the hospital, whilst non-urgent cases are classified as inappropriate. However, nonurgent attendances may overestimate the episodes that can be avoided by relying on primary care services only, since a fraction of non-urgent visits may still require hospital or specialist care. Alternatively, one can utilize ad hoc information on disease severity and complexity to identify inappropriate ED attendances. This strategy can be pursued when an on-site clinical assessment based on triage codes establishes whether the use of the emergency services is justified or not. Under these more restrictive criteria, the share of inappropriate ED visits is reported to range between $20 \%$ and $80 \%$ of all non-urgent cases (Afilalo et al., 2004). Despite differences in the estimated magnitude of the phenomenon, the overall consensus in the literature is that a relevant fraction of emergency visits could also be treated effectively in less intensive settings. When hospitalisations are filtered by the GP, this also calls into question the accuracy of gatekeeping, and suggests that a better designed primary care system, ensuring improved access to family physicians, may help contain the (excessive) use of EDs.

The present paper investigates the determinants of ED attendances using administrative data for the year 2009 in Italy's Emilia-Romagna Region. Our data include information on GPs' characteristics and on patients' use of healthcare services. By exploiting the link between GPs and their listed patients, we study to what extent practice characteristics and organisational arrangements influence the demand for emergency services. The paper's main goal is to assess whether, after controlling for relevant confounders, differences in day-time accessibility to primary care are associated to different utilisation rates of ED services by 
registered patients. In particular, we analyse whether programmes that extend the availability of GPs' primary care services to between 10 and 12 hours/day, are effective in containing the number of those ED visits not followed by hospitalisation. We consider different ways of measuring ED attendances, all recorded at list level. Moreover, since participation in the opening hours extension programme is voluntary, we also adopt empirical strategies in order to take account of the potential endogeneity of participation, using a twostage residual inclusion (2SRI) specification and a GMM approach.

Our paper contributes to the literature in several ways. First of all, the organisation of the Italian NHS, and the use of databanks covering the entire regional population, enable us to investigate the link between primary care organisation and emergency services on a large scale, whereas most existing studies rely on survey data and small samples. Secondly, our work adds to the literature that studies whether the strengthened role of primary care policies and GPs can foster a more appropriate utilisation of hospital services by containing admission rates (e.g. Dusheiko et al., 2011; McCormick and Nicodemo, 2014). Thirdly, we overcome part of the limitations associated with the use of imprecise measures of inappropriateness in ED utilisation. One advantage this study has over previous ones is that we have access to information which enables us to formulate alternative definitions of inappropriate ED visits. A narrow definition includes only those episodes classified as inappropriate according to on-site clinical assessment based on the Italian triage system (white codes). A broader definition utilises additional information on the intensity of treatment received at EDs and pools together white codes with the attendances not classified as such but which receive only a general check-up with no diagnostic or specialist follow-up (potentially inappropriate visits). Finally, from a methodological viewpoint we identify relevant instrumental variables for GPs' participation in the (voluntary) programme promoting the extension of practices opening hours. By doing so, we test for the potential endogeneity of the variable of main policy interest, and account for the possible bias due to GPs' own decision to participate in the programme. We thus tackle an empirical challenge frequently encountered in the literature on programme evaluation both in specialist and primary care, which often examines cases where physicians' participation in such programmes is not mandatory (e.g. Grytten and Sorensen, 2001; Propper et al., 2002; Dusheiko et al., 2006; Devlin and Sarma, 2008; Fortin et al., 2010).

Our main findings indicate that organizational characteristics of the practice affect ED attendances. In particular, we find that an extension in practices' day-time opening hours and the consequent increased accessibility to primary care services, is effective in containing the use of ED wards. As expected, the magnitude of the estimated effect is larger for both measures of avoidable episodes (i.e. white codes and potentially avoidable admissions) than for total visits. We also consider different specifications and econometric methods to test for endogeneity of the dummy variable that captures voluntary participation in the extension program. Our findings suggest that in our data endogeneity is not an empirical concern for the two measures of avoidable admissions to the ED. 


\section{Background Literature}

Most studies of ED utilisation focus on patients' characteristics as determinants of the use of emergency services. At this regards, poverty and minority status are shown to increase the likelihood of people attending EDs for non-urgent care (Lang et al., 1996). However, other studies show that ED attenders more often than not belong to the middle and upper classes (Shah et al., 1996; Lee et al., 2000). Furthermore, cost sharing significantly reduces admissions, although the size of the copayment has little effect on ED utilisation (Roberts and Mays, 1998). Other studies have shed light on patients' reasons for not seeing their GP and for self referring to the local ED. The main such reasons include the need for immediate care and relief, although difficulties in accessing primary care also play an important role in such decisions. Lee et al. (2000) identify the closure of GP's practices at night as one of the primary reasons for high ED attendances, thus stressing the importance of out-of-hours services. Moll van Charante et al. (2008) report that shorter waiting times and greater proximity are among the principal reasons for attending the ED and these findings are in line with Puig-Junoy et al. (1998) who show that substitution patterns between ED and GP visits are particularly intense in response to lengthy waiting times to see local GPs. From a different perspective, Carlsen et al. (2007) detect a negative relationship between patient satisfaction with primary care and emergency admissions. Similar evidence emerges from Sempere-Selva et al. (2001), Guttman et al. (2003) and McCusker et al. (2010). However, so far very few studies have addressed the Italian case. An exception is Lega and Mengoni (2008) who use questionnaires distributed within one single Italian province, and find that ED users are attracted by the opportunity to receive a prompt specialist consultation, especially when they do not trust their GP and are not satisfied with opening hours.

As regards the role played by physicians' organisations, most empirical research is based on US data and its findings cannot be straightforwardly extended to NHS countries. Using Medicaid patients, Lowe et al. (2005) estimate that overall ED use would decrease by 13\% if all practices opened 12 or more evening hours a week, and by a further $5 \%$ if they also opened at weekends. Moreover, studies based on data provided by Kaiser Permanente and the Veterans Administration suggest that the integration of primary care with hospital-based services may reduce utilization of ED services (Feachem et al., 2002; Armstrong et al., 2006). In the case of the UK, the impact of practices' organisation seems of a limited entity, as patients' characteristics account for most of the variation in use of EDs (Saxena et al., 2006; Calderòn-Larranaga et al., 2011). Harris et al. (2011) conduct a cross-sectional ecological study of one Primary Care Group, whereby they test whether ED attendance can be explained by varying accessibility to GP practices proxied by total opening hours per week. None of the proxies for accessibility turns out significant, thus suggesting that the use of the ED is probably driven by the underlying characteristics of users, including that of social deprivation. Focusing on out-of-hours primary care services, Thompson et al. (2010) find little change in ED attendances attributed to their introduction in 2004. The Netherlands' reorganization of primary care in 
favour of large-scale GP cooperatives capable of providing out-of-hours assistance, appears more successful: examining a population of 62,000 people during two four-month periods over a five-year interval, Moll van Charante et al. (2007) show that the GP cooperatives are able to deal with the vast majority of out-of-hours requests whereas self-referrals to ED represent a small group of patients that attend hospitals mainly for appropriate reasons.

Overall, the literature shows that the underlying reasons for high ED attendance rates are varied, and to a certain extent reflect health needs unmet by primary care, including the frustration with scheduling appointments and lengthy waiting times, the perception of long waits before gaining access to other secondary services, and greater trust in hospital care.

\section{Primary care in the Italian National Health Service}

\subsection{The institutional framework and GPs' payment scheme}

The Italian National Health Service (NHS) was established in 1978 to replace a Bismarckian health care system with a Beveridgian system based on the principles of universalism, comprehensiveness and equity. Health expenditure is relatively low according to international standards: public health expenditure amounts to $6.9 \%$ of GDP in 2013 , whereas total health expenditure accounts for $9.1 \%$ of GDP, which is slightly below the OECD average of 9.3\% (OECD, 2014). Despite this, in the 1990s Italy's high public debt led to the implementation of a series of reforms aimed at enhancing efficiency and containing costs. One major change consisted in the progressive regionalisation of the NHS, giving Italian regions substantial political, administrative and financial responsibility for the organisation and delivery of public health care.

In Italy, primary care is organised according to a list-based system, and family physicians are independent contractors with the NHS delivering care to registered citizens and acting as gatekeepers to specialist and hospital care. Primary care services are free of charge at the point of need, while registration with family physicians is compulsory. Individuals can choose their GP and are free to change him, although in practice the turnover rate is very low, and most of the (few) observed changes are the consequence of patients moving their residence rather than of any dissatisfaction with their GP (Italian Ministry of Health, 2010). Each GP has a maximum list size of 1,500 registered patients. Capitation is the main income source for family physicians, and it is negotiated at national level every three years. The payment scheme is organised with a variable and an additional component that top up capitation. The variable part consists of fee-for-service payments for specific types of treatment, including minor surgery, preventive care and post-surgery followup. The additional part is designed with a considerable degree of autonomy by Regions and it is used as a reward for high quality, appropriate care or for adherence to cost-containment policies (Lo Scalzo et al., 2009; Fiorentini et al., 2011, 2013). By doing so, policymakers want to favour the alignment of physicians' 
incentives to general policy goals. It is also interesting to remark that in the institutional context that we consider, no additional payment for containing ED admissions has been introduced so far.

\subsection{Primary care and inappropriate ED utilisation}

As in most developed countries, the NHS in Italy faces the problem of the intense, often inappropriate, use of EDs (Ameri et al., 2011). One response to this problem has seen policymakers introducing a triage system for those ED attendances not followed by hospitalisation, whereby patients' conditions are assessed by ED staff, and a given case can be classified as inappropriate (white code), resulting in it being treated as a low priority case (Levaggi and Montefiori, 2013). More recently, an additional strategy has built on the view that improved accessibility to primary care could meet part of the demand from patients who would otherwise self-refer to the ED. Since the national contract sets relatively low requirements in terms of practice opening hours, the new policy focuses on extending such hours during day time on week days ${ }^{1}$. Unlike in other countries, the policy does not ensure access out of hours or at weekends. This reform is based on the idea that if daytime practice opening hours were extended, this would reduce the frequency of emergency admissions, and in particular of inappropriate ones. However, empirical findings regarding the effectiveness of these measures are still lacking, and the present work aims to fill this gap.

Nevertheless, the coordinated extension of GP practice hours is only one of the measures characterising the provision of primary care by the Italian NHS. Since the mid-1990s great efforts have been made to encourage cooperation among GPs, and between GPs and hospital providers. The purpose of establishing various forms of partnerships among GPs was to improve the quality and comprehensiveness of care (Shaw and Meads, 2012). Indeed, individual practices are believed to be less effective in providing high quality care than those practices run by a coordinated team of GPs, due to the limited opportunity to guarantee any continuity of care to chronic patients (Fantini et al., 2012), and to acquire diagnostic equipment. Such forms of cooperation entail not only substitution in the event of a fellow doctor's illness, but also the sharing of premises and staff (Fattore et al., 2009).

As regards Emilia-Romagna, a later policy phase was launched in 2007 aimed at encouraging the coordination of practice opening hours and ensuring an overall daily coverage by the group as a whole of up to 12 hours. This measure targeted GPs who had previously been members of professional groups, since the coordination of opening hours entails close cooperation, which requires formal connections among physicians. In the light of this, our study evaluates the impact on ED attendance of the extension of practice opening hours among GPs belonging to professional groups. Given this feature of the policy, we do not cover the entire population of GPs working in the Region, but concentrate on those who were already members of groups in 2009. It is important to note that even when their GP is involved in such group

\footnotetext{
${ }^{1}$ To provide a benchmark of reference, individual GPs are required to open their practice only for (a minimum of) 15 hours a week.
} 
arrangements, patients maintain their registration with a specific physician and not with the group as a whole. Therefore, the use of hospital services can be univocally correlated to the GP patients are registered with. From the patient's point of view, the main advantage of being registered with a GP participating in the extension programme consists in the possibility of obtaining initial care from another member of the group if the GP in question is not available at a particular time of day. Furthermore, GPs substitute each other in cases of absence and, as clinical records are shared electronically among group members, the substitute can access patients' clinical histories.

\section{Data}

\subsection{The data}

Given the nature of our data and the purpose of the paper, the GP is chosen as a unit of analysis. Our study population consists of all GPs working in groups and operating in the Region in 2009. We excluded any physicians with fewer than 200 registered patients from the sample, since their involvement in primary care can be considered a part-time activity. Overall, we have 1,082 GPs belonging to a group, out of a total of 3,113 GPs. Physicians who are part of a group, and those who are not, are fairly similar in terms of observables, including personal characteristics (54.8 vs. 55.0 yrs. GP's age; 21.3 vs. 21.0 yrs. seniority; $73.4 \%$ vs. $69.9 \%$ share of male GPs) and list characteristics (51.0 vs. 50.7 patients' avg. age; $47.8 \%$ vs. $47.9 \%$ share of males; $6.9 \%$ vs. $8.2 \%$ share of foreigners), although those working in groups have a slightly larger list size (1,266 vs. 1,152 patients).

Our data provide information for the year 2009 on patients' attendances of regional EDs that are not followed by hospitalisation. The data are routinely collected for administrative reasons and each patient is characterised by an individual, encrypted identification number used to link the medical-use records for ED services to his GP. Furthermore, we use information concerning the treatment received at the ED, which allows us to establish whether it consisted only in a general visit or if it entailed subsequent diagnostic or specialist examinations. We consider three alternative measures for ED attendances as our dependent variables: the visits classified as inappropriate according to the Italian triage system (white code visits); the sum of white codes and those episodes which, although not coded as such, consisted merely in a general visit with no diagnostic or specialist follow-up (potentially inappropriate visits); the overall number of ED visits not followed by hospitalisation (total visits). As regards the first indicator, the Italian triage code system classifies as "white codes" the episodes of inappropriate access on the basis of specific clinical standards defined by an institutionally-coded rule at the national level. While the white-code classification is established nationwide, the second, wider measure of potential inappropriateness that pools together white codes and non-white episodes requiring only minor attention, is the one adopted by the Department of Health 
to monitor the regional emergency system. ${ }^{2}$ As for total visits, the reason for including it in the analysis is that they provide a comprehensive picture of the overall congestion of emergency services, although they are only of minor interest here since the policy under investigation was aimed at addressing mainly the episodes of avoidable use of the ED represented by white codes and potentially inappropriate visits.

The set of controls includes the gender and seniority of the GP, while we exclude age because of its correlation with seniority. ${ }^{3}$ We add a dummy for the presence of nursing staff in the practice, and we control for practice location and geographical accessibility by including the distance between the premise and the closest ED (Chauhan et al., 2012), together with a dummy for practices in (totally or partially) mountainous municipalities. An additional set of variables relates to list characteristics. We specify list size as an offset variable (Chauhan et al., 2012) to account for heterogeneous exposure to the probability of ED admissions which derives from the variability in the number of registered patients across GPs. We then consider the share of patients who are male, and the average age of those on the list ${ }^{4}$. The share of foreign patients is expected to account for the influence of cultural differences and of health literacy on the propensity to use the ED compared to alternative solutions such as seeing one's GP. An open issue in the empirical literature on primary care is how to control for the case-mix of the list. Because of data limitations, most studies control for age and gender composition only, whereas we include also admission rates measured at list level to better proxy list severity. To avoid simultaneity bias, we consider hospital admissions for the previous year (2008). ${ }^{5}$ As for the variable of main policy interest, we include a dummy with a value of 1 if the GP works in a group subscribing to the programme for the coordination of practice opening hours. Finally, unobserved local effects are controlled for by including dummies for the sub-areas into which the region is divided, and that are in charge of coordinating health care policies at the local level (Iezzi et al., 2014).

\subsection{Descriptive Statistics}

Table 1 shows the descriptive statistics for the dependent, control and instrumental variables used in our estimates. The data refers to the sample of 1,082 GPs working in groups and having more than 200 listed patients each. Less than one third of GPs in our sample (29.8\% ) extended their opening hours to up to 10/12 hours. We compare the different subsets of physicians by displaying information separately for the 760 GPs in groups that do not extend the opening hours, and for the 322 GPs that belong to groups that organize themselves so as to offer patient services between 10 and 12 hours per day. We also test formally for

\footnotetext{
${ }^{2}$ Levaggi and Montefiori (2013) analyse cost data on 1011 patients treated at a single Italian ED ward (Ospedali Galliera in Genoa) and highlight that laboratory tests and the number of examinations are the key driver of costs. As a consequence they pool together white coded episodes and non white episodes which received no lab tests in a unique category homogenous not only in terms of risk of inappropriateness but also of resource use.

${ }^{3}$ The presence of a non linear effect for seniority has been tested by including a quadratic term. However, this was excluded from our final specification since it never turned out as significant.

${ }^{4}$ The quadratic term for average age of the list never resulted as being significant and was excluded from our specification.

${ }^{5}$ The events used to create the hospitalisation variable do not overlap with those used for our dependent variables, as the latter consider only visits to the ED not followed by hospitalisation.
} 
differences in means between the two groups using a standard $t$-test for mean comparison between groups allowing for unequal variances. The $p$-values for the test are reported in the last column of Table 1.

\section{TABLE 1}

Our sample comprises a total of 408,306 ED admissions, 77,205 of which were assigned white codes (19\% of the total) while 163,205 fall under the heading of potentially inappropriate visits according to the aforementioned principle of summing those patients receiving only a general visits to those assigned white codes ( $40 \%$ of the total). The average number of attendances per GP amounts to 377, while 71 are the whitecoded cases and 151 the potentially inappropriate attendances. When we consider the sub-samples of those GPs who extended their opening hours and those who did not, we see the following differences: 349 vs. 389 for total attendances, 53 vs. 79 for white codes, and 121 vs. 163 for potentially inappropriate visits, respectively. According to the $t$-test, all these differences are statistically significant.

In the estimating sample, about $73 \%$ of GPs are male and the average list size is above 1,265 patients, although list size varies considerably. The proportion of non-native patients (around 7\%) is in line with census data. In this context, it is important to control for the ethnic composition of the list, since natives and foreigners often display different patterns of healthcare service utilization, including emergency services, for cultural and socio-economic reasons (Jimenez-Rubio and Hernandez-Quevedo, 2011; Devillanova 2012). Around one fourth of the GPs employs nursing staff, while nearly 30\% of practices are in municipalities located in totally or partially mountainous areas, which may create additional geographical barriers for any rapid access to the nearest ED. The $t$-test $p$-values indicate that the two groups possess fairly similar observable characteristics at both GP and list level. Some differences in the explanatory variables regard the presence of nursing staff, practice's location in mountainous areas and the share of male patients in the list.

\section{Econometric Strategy}

\subsection{Specification of the model}

Let $y_{i}$ be the count variable of interest, namely each of the three measures of ED attendances discussed above. Admissions are aggregated at the GP level, leading to large values for the count means. As standard in the count data estimation, we specify the conditional mean of $y_{i}$ in an exponential form and we also allow and test for over-dispersion.

Assuming that $y_{i}$, the count variable of interest, is Poisson distributed, we have:

$$
P\left(y_{i}=q\right)=\frac{e^{-\mu_{i}} \mu_{i}^{q}}{q !}
$$


where the parameter $\mu_{i}$ is both the mean and the variance of $y_{i}$, so that $\mu_{i}=E\left(y_{i}\right)=\operatorname{Var}\left(y_{i}\right)$ (equidispersion property of the Poisson distribution). In a Poisson regression, $\mu_{i}$ is modelled as an exponential function of a set of covariates $\boldsymbol{x}_{\boldsymbol{i}}$ such that $\mu_{i}=\mu_{i}\left(\boldsymbol{x}_{\boldsymbol{i}}\right)$.

We thus have

$$
E\left(y_{i} \mid \boldsymbol{x}_{\boldsymbol{i}}\right)=\mu_{i}=\exp \left(\boldsymbol{x}_{\boldsymbol{i}}^{\prime} \boldsymbol{\beta}\right)
$$

In our empirical analysis, the vector of regressors $x_{i}=\left(x_{1}, x_{2}, \ldots, x_{\mathrm{p}}\right)$ consists of the variables presented in Table 1, and includes a dummy extop for the extension of practice opening hours, which is the indicator of main policy interest, and the list size in logarithms as an offset variable. The estimating model is the following:

$$
y_{i}=\exp \left(\boldsymbol{x}_{\boldsymbol{i}}^{\prime} \boldsymbol{\beta}\right)+\varepsilon_{\mathrm{i}}=\exp \left(\beta_{0}+\beta_{1} \text { extop }_{\mathrm{i}}+\beta_{2} x_{\mathrm{i} 2}+\ldots+\beta_{\mathrm{p}} x_{\mathrm{ip}}+\ln (\text { listsize })\right)+\varepsilon_{\mathrm{i}}
$$

where $\varepsilon_{\mathrm{i}}$ is the random error of the model and the coefficient on $\ln$ (listsize) is constrained to 1 as the size of the list represents the exposure term. In fact, the number of patients captures, for each GP, the population at risk of attending the ED.

Under standard assumptions, equation (3) can be consistently and efficiently estimated using Maximum Likelihood (ML) if the equi-dispersion assumption holds. However, the latter assumption is in general too restrictive and it is often violated in empirical applications, especially when cross-sectional data are affected by unobserved heterogeneity (Trivedi, 2014). This is also the case in our data where the summary statistics for the dependent variables provide evidence of over-dispersion in our sample, as the variance is around 40 times the average. In the case of over-dispersion, a Negative Binomial (NB) specification is preferable to fit equation (3). The NB model is obtained by substituting the parameter $\mu_{i}$ in the Poisson distribution with $\mu_{i} v_{i}$, where $v_{i}$ captures individual-specific unobservable heterogeneity that enters multiplicatively the conditional mean of $y_{i}$ (Trivedi, 2014), such that:

$$
E\left(y_{i} \mid \boldsymbol{x}_{\boldsymbol{i}}, v_{i}\right)=\mu_{i}\left(\boldsymbol{x}_{\boldsymbol{i}}\right) v_{i}=\exp \left(\boldsymbol{x}_{\boldsymbol{i}}^{\prime} \boldsymbol{\beta}\right) v_{i}
$$

If a Gamma distribution for the latent factor $v_{i}$ is assumed with mean 1 and variance $\alpha$, the resulting NB2 model is a mixture model with mean $E\left(y_{i} \mid \boldsymbol{x}_{\boldsymbol{i}}, \alpha\right)=\mu_{i}\left(\boldsymbol{x}_{\boldsymbol{i}}\right)$ and variance $\operatorname{Var}\left(y_{i} \mid \boldsymbol{x}_{\boldsymbol{i}}, \alpha\right)=[(1+$ a $\mu i \boldsymbol{x i}] \mu i \boldsymbol{x i}$, which comes out to be larger than $\mu i \boldsymbol{x i}$.

In our empirical strategy, we test for over-dispersion by testing $H_{0}: \alpha=0$ against the alternative $H_{a}: \alpha>0$ by means of a $\chi^{2}$-likelihood ratio test (Cameron and Trivedi, 2013). If the over-dispersion parameter $\alpha$ is not significantly different from zero, the NB2 distribution reduces to the Poisson. The null hypothesis of equidispersion is always rejected in our data and the test strongly supports the evidence of over-dispersion, confirming that the NB2 specification is the preferred one in this context. 
As an additional robustness check, we also estimate a linear specification of the outcome model by OLS. To preserve consistency with a count data specification with varying exposure, we consider as dependent variable the ratio between the number of attendances, aggregated at the GP level, and the number of patients registered on the GP's list, that is $y_{i} /$ listsize, which measures the average number of ED visits per patient for each GP. Table 2 reports the NB2 estimates of the model in (3) for each of the three dependent variables; in addition, we also include the Poisson estimates, the OLS estimates and the results of the tests for overdispersion.

\subsection{Potential endogeneity of the policy variable and exclusion restrictions}

As the groups of GPs are free to choose whether to extend opening hours, the participation dummy is potentially endogenous. In fact, we cannot rule out the possibility that unobserved factors affect, at one and the same time, GPs' propensity to participate in the extension programme, and patients' frequency of attendance of EDs. This may depend for instance on (unobserved) differences in practice style: GPs more aware of the importance of providing preventive care and effective counselling may be keener to take part in the extension programme. Consequently, different frequencies of ED attendances may be due to the physicians' practice style, rather than to the effect of observed factors, and this may render the identification of a causal link between extension and ED admissions problematic. This is an empirical concern, since ML only provides consistent estimates under exogeneity of the regressors. Failure to meet this assumption would also undermine the policy implications of the estimated effect of the extension.

The proper way to deal with unobserved heterogeneity of this kind is to adopt Instrumental Variables (IVs) methods. However, identifying potential candidates for valid instruments is often challenging, even more so in our case where information has to be linked consistently across a number of different databanks. Still, we can take advantage of the features of the extension programme, which relies on consolidated cooperative agreements among GPs. Two organizational characteristics of the groups in question emerge as natural candidates for our instrumental variables: the number of physicians participating in the group, and the number of years since the GP first joined a group.

The institutional characteristics of the system support our choice. As previously remarked, our analysis focuses exclusively on physicians working in groups, since the extension programme does not apply to single-handed practices. The coordination of opening hours represents a further step in cooperative agreements, compared to mere involvement in a group. It is a rather challenging task which can be highly demanding in terms of the coordination of the activity of each GP, and of the joint professional effort involved. In particular, such effort becomes greater when the group is composed of a limited number of GPs, whereas larger groups can share the burden of longer opening hours among a larger number of physicians.

Table 1 reports the descriptive statistics for the two instruments in detail and shows that the groups participating in the programme are on average over $20 \%$ larger than those that do not extend their opening 
hours (5.44 vs 4.42 members), thus confirming that larger groups are keener to take up the extension option. Following the same line of reasoning, physicians that have been working for several years as a group may find it easier to participate in the extension programme since their collaborative routines have been running successfully for longer than in the case of those physicians who have only recently established a group. GPs extending opening hours have been working in a group for almost 8.5 years on average, while those not subscribing to the programme have been in a group for 7.5 years on average. The differences between groups are statistically significant for both variables, according to the standard $t$-test.

In Emilia-Romagna, the transition from individual to group practices has been particularly intense since the mid-1990s, although a number of pioneering experiences date back even further, to a few years before then. Two factors are particularly important within this context. From their creation onwards, the structure of such groups has been highly stable, with basically no cases of GPs reverting back to working individually, and very few cases of group reconfiguration. In general, the size of the groups had already been established prior to the advent of the opening hours extension programme, and did not undergo any real change as a consequence of the announcement of this new policy. Moreover, in 2009 the vast majority of GPs in group practices had been cooperating for a considerable number of years already, as shown by the average figures reported above. These features lend support to the idea that the organisation of the groups is exogenous to the policy in question.

\subsection{Instrumental variable estimation}

As extensively discussed in the previous section, the participation dummy is potentially endogenous, due to a correlation with unobservable factors, and proper instrumental variables need to be identified. To accommodate this potential correlation, we model the presence of unobservable factors by introducing an additional latent confounder $x_{\mathrm{iu}}$ in equation (3).

The model of interest thus become:

$$
y_{i}=\exp \left(\beta_{0}+\beta_{1} \text { extop }_{\mathrm{i}}+\beta_{2} x_{\mathrm{i} 2}+\ldots+\beta_{\mathrm{p}} x_{\mathrm{ip}}+\rho x_{\mathrm{iu}}+\ln (\text { listsize })\right)+\varepsilon_{\mathrm{i}}
$$

where extop is potentially correlated with $x_{\mathrm{iu}}$.

Count data specifications constitute a particular challenge to the implementation of IV methods (e.g. Windmeijer and Santos Silva, 1997). Unfortunately, the linear IV estimator (2SLS) has severe drawbacks in this framework. Terza, Bradford and Dismuke (2008) show that addressing endogeneity by applying conventional linear IV methods that ignore the non-linear specification of the relationship of $y$ to an endogenous regressor, and a set of additional confounders, can lead to biased estimates of the causal effect in question.

Mullahy (1997) and Terza, Basu and Rathouz (2008), among others, have suggested alternative estimators in order to deal with endogeneity in count/exponential regression models. In keeping with these studies, we 
employ two different IV strategies to estimate the model in (5) where the (binary) regressor extop is allowed to be endogenous to the outcome variable.

We first adopt a 2-stage residual inclusion (2SRI) strategy; secondly, we consider a moment-based GMM (Generalized Method of Moments) estimation procedure. Both estimators yield consistent estimates of the coefficients in the presence of endogeneity, whilst allowing unobservable confounders to be correlated with the included regressors, and requiring only weak structural assumptions regarding the data-generating process.

\subsubsection{Two-stage residual inclusion}

The 2SRI proposed by Terza, Basu and Rathouz (2008) is a version of the more general control function approach common to econometric applications, and first developed for count data model by Wooldridge (1997, 2010). Terza, Basu and Rathouz (2008) extend the previously suggested residual inclusion strategies (Rivers and Vuong, 1988; Smith and Blundell, 1986) to a broader class of nonlinear models. This structural equation approach can also be interpreted as an extension of the Hausman (1978) endogeneity test suitable for non-linear models. Indeed, when dealing with a potentially endogenous variable, exogeneity in a nonlinear model can be tested through an asymptotically-efficient Wald test on the coefficients of the firststage residuals included in the second-stage (Smith and Blundell, 1986). The test on the first-stage residuals enables to determine the extent to which unobserved latent factors affect the outcome (Pizer, 2009).

Following Terza, Basu and Rathouz (2008), we illustrate the 2SRI strategy in detail.

As argued above, the main econometric issue to be addressed is the potential correlation between extop and the unobservable factor $x_{\mathrm{iu}}$ in (5), which is the source of endogeneity we are concerned about. If the latent factor $x_{\mathrm{iu}}$ was observable, it would be included among the regressors in (5); however, as it is not, it has to be replaced by a consistent estimate that can be obtained from the first stage. Once a vector $\boldsymbol{z}_{\mathrm{i}}$ of instrumental variables is selected, at the first stage, we estimate a reduced form for extop. Being extop dichotomous, a proper reduced form for the probability of extending opening hours is:

$$
\operatorname{Pr}\left(\text { extop }_{\mathrm{i}}=1\right)=g\left(\gamma_{0}+\gamma_{2} x_{\mathrm{i} 2}+\ldots+\gamma_{\mathrm{p}} x_{\mathrm{ip}}+\delta_{1} \text { sizeprac }+\delta_{2} \text { yearsgroup }\right)+x_{\mathrm{iu}}
$$

where sizeprac and yearsgroup are the two instrumental variables previously discussed and excluded from the outcome model in (5), $x_{\text {iu }}$ represents unmeasured latent factors affecting both extop and $y$, and $x_{\mathrm{i} 2}, \ldots, x_{\mathrm{ip}}$ are the observable covariates other than the participation dummy. For dichotomous indicators, the function $g$ usually adopted is the probit or the logit but it can also be assumed to be a linear function so that (6) becomes the standard LPM. The residuals from equation (6), defined as $\hat{x}_{\text {iu }}$, provide a consistent estimate of $x_{\mathrm{iu}}$ in equation (5) and can be included as regressors in the outcome model. As discussed in Basu and Manning (2009) and in Garrido et al. (2012), there is not an agreement in the literature on the appropriate specification of the residuals, and additional research is required as the results in the second stage estimation 
may be sensitive to the choice of the residuals. Given the lack of consensus on this point, we present here estimates that consider alternative specifications of the residuals $\hat{x}_{\mathrm{iu}}$. For any of the probit, logit and linear forms for $g$, we compute the response or raw residuals, which are currently the most common choice in empirical applications of the 2SRI method, as:

$$
\hat{x}_{\mathrm{iu}}=\operatorname{extop}_{\mathrm{i}}-\operatorname{Pr}\left(\operatorname{extop}_{\mathrm{1}} \widehat{=1}\right)
$$

In addition, we also calculate the generalised residuals (Gourieroux et al., 1987) and the deviance residuals for the probit link, and the standardised Pearson residuals for the logit.

Based on the first-stage estimates, we test for the joint relevance of the IVs by means of a $\chi^{2}$ test in the logit and probit specifications an F-test in the LPM case. Table 3 reports the first-stage estimates.

In the second stage, the unobserved factor $x_{\mathrm{iu}}$ in model (5) is replaced by the first stage residual $\hat{x}_{\mathrm{iu}}$ which represents a consistent estimate for it, so that the estimating equation becomes:

$$
y_{i}=\exp \left(\mathrm{b}_{0}+\mathrm{b}_{1} \text { extop }_{\mathrm{i}}+\mathrm{b}_{2} x_{\mathrm{i} 2}+\ldots+\mathrm{b}_{\mathrm{p}} x_{\mathrm{ip}}+\mathrm{\varrho} \hat{x}_{\mathrm{iu}}+\ln (\text { listsize })\right)+\epsilon_{\mathrm{i}}
$$

where we keep extop among the regressors. We estimate the model in (8) by NB MLE by allowing for different specification of $\hat{x}_{\mathrm{iu}}$. The inclusion of the residuals from the reduced form in the second stage regression has a twofold advantage: on the one hand, it provides a straightforward Wald exogeneity test for the potentially endogenous variable within a nonlinear framework; on the other hand, it controls for the endogeneity of the participation dummy induced by correlation with unobserved factors. A coefficient $\varrho$ statistically different from zero would provide evidence of the presence of underlying unobserved factors affecting both the opening and the outcome variables. Finally, to account for the fact that we include residuals from a first-stage estimation among the regressors in the second stage, standard errors for the outcome model coefficients are bootstrapped. Table 4a-c present the second stage estimates for the 2SRI method for each of the three dependent variables considered.

\subsubsection{GMM estimation}

The GMM estimator is potentially appealing in a nonlinear context as a straightforward transposition of the conventional linear IV estimator, but it is generally unfeasible for nonlinear models. The only functional forms for which the GMM is feasible are the linear and the exponential ones (Terza, 2006; Terza, 2014). Beyond its feasibility, for exponential count data models the GMM estimator has not only the advantage of being feasible but also of requiring neither assumptions about equi-dispersion or over-dispersion, nor assumptions about the reduced form for the endogenous variables. Furthermore, it gives consistent estimates also when the endogenous variables are binary.

Taking advantage of these attractive features, we estimate here the model in (5) by GMM, by means of exploitable moment conditions which ensure consistent estimates for the coefficient of extop, provided that valid instruments are available. Mullahy (1997) derives suitable orthogonality condition for a symmetric 
model such as that in equation (5), where the unobservable confounder $x_{\text {iu }}$ enters the model in the same way as the observable confounders, and is treated as a regressors in the exponential function (Mullahy, 1997; Terza, 2006). Mullahy (1997) proves that, if the instrumental variables in the vector $\boldsymbol{z}_{i}$ are relevant and exogenous to the outcome model, it is possible to construct a consistent GMM estimator that exploits the following orthogonality conditions:

$$
E\left[\left(\frac{y_{i}}{\exp \left(\beta_{1} \text { extop }+\beta_{2} x_{\mathrm{i} 2}+\ldots+\beta_{\mathrm{p}} x_{\mathrm{ip}}+\ln (\text { listsize })\right)}-1\right) z_{i}\right]=0
$$

where the included regressors are the same as in outcome model.

As the vector $\mathbf{z}$ includes two instrumental variables, the model is over-identified and we test the validity of the orthogonality conditions using the standard Hansen test for overidentifying restrictions. Tables 5 reports the two-step GMM estimates for the model in equation (5) and the Hansen test statistics and $p$-values.

\section{Results}

\subsection{Baseline estimation}

In this section we discuss the main results of our estimation strategy for the model in equation (3). We run Negative Binomial, Poisson and OLS regressions for each dependent variable used in the study (white codes, potentially inappropriate visits and total visits), and all the results are reported in Table 2. As we deal with count data and the likelihood-ratio test on the NB parameter $\alpha$ highlights the presence of over-dispersion, the NB model comes out as our preferred specification. Consequently, we focus our discussion on the NB results.

\section{TABLE 2}

The first important finding is that the dummy for extended opening hours always displays a negative and significant coefficient irrespective of which measure is used as dependent variable and of the model specification. We find sizeable differences in the magnitude of the estimated effect between the white codes and potentially inappropriate admissions, on the one hand, and total number of visits, on the other hand, with a relatively lower value when we consider total visits. In terms of Incidence Ratio Ratios (IRRs), the participation in the programme is estimated to reduce white codes attendances by $6.6 \%$, while the reduction is $8.4 \%$ for potentially inappropriate admissions. As for total visits, the IRR points out a reduction in ED utilisation by only $3.2 \%$. The Average Marginal Effects calculated for the white codes show that participation in the extension programme leads to an estimated average annual reduction in ED visits per GP of about 4.8 episodes. The extension programme provides an average estimated reduction in potentially inappropriate visits of around 13 episodes. Interestingly, this reduction is very close to the one estimated for total admissions (12.1 episodes) confirming that the extension of practices availability affects inappropriate 
episodes rather than the more serious cases. This finding is consistent with the idea that a measure encompassing a wider range of cases, such as total admissions, which also includes appropriate use of the ED, should be less affected by the extended availability of primary care. Overall, the variable of main policy interest is always significant and the evidence we draw from the data indicates that the extension programme has been effective in reducing the frequency of avoidable ED visits.

As for the impact of individual characteristics of GPs on the pattern of ED utilisation, we find that GPs with longer professional experience record a lower number of inappropriate visits to the ED by their patients. In general male GPs are associated with lower counts, even though the effect is not always significant across specifications. With respect to the presence of nursing staff, the estimated coefficient is highly significant and indicates that practices employing nursing personnel prove to be better at helping prevent inappropriate attendances. Relative accessibility to the ED and to the practice also play an important role. Since we do not have information on patients' place of residence, we take the distance between the practice and the closest ED as a proxy for patients' geographical accessibility to the latter. The reason for this comes from the fact that citizens usually enrol with a physician close to their home. Practice location can thus be taken as a proxy for patient residence and we expect that individuals registered with GPs located closer to the ED are faced with shorter travelling times than those patients registered with physicians located further away from the ED. Interestingly, the distance effect gets smaller when we move from white codes and potential inappropriate visits to total admissions: this finding is in line with expectations, since distance is likely to discourage the least severe cases more. The coefficient for practices located in mountainous municipalities is positive and significant for white-codes and potentially inappropriate visits. This may reflect the fact that patients in such areas are faced with higher costs for seeing their GP than urban residents are, and once we control for the distance between the practice and the hospital, a more frequent use of ED services instead of outpatient facilities is more likely.

Finally, statistically significant effects emerge also for the characteristics of the GP's list. The estimated number of visits to the ED is in most cases negatively correlated to the average age of patients. This suggests that patients with a lower opportunity cost of time, such as the elderly, who enjoy regular access to their GPs, use ED services less frequently than younger patients do. This indication is consistent also with the positive impact on ED attendances of a higher proportion of males on the list. Furthermore, foreign patients also display higher ED attendance rates. Finally, previous hospitalisations used as a proxy of severity do not affect the number of visits.

\subsection{Instrumental variable estimation}

In order to test and control for the potential correlation between the decision to extend opening hours and unobserved factors that may affect the outcome variable, we implement the IV strategies discussed in the previous sections. In this way, we address the potential endogeneity resulting from non-random participation in the programme. 
Following the 2SRI approach, we first estimate the reduced form in equation (6) for the probability of extending practice opening hours. Our exclusion restrictions, necessary for identification, require that the instrumental variables affect participation into the programme, but are not related to the use of emergency services. The choice of the IVs has been motivated in section 5.2: the two instruments are group size, which measures the number of physicians participating in each group, and the number of years each GP has been working in the group. In the second stage, we use the residuals from the first stage equation as an additional covariate for the outcome equation. The residuals are consistent estimates for unobserved latent factors affecting both the outcome variable and the dummy for opening extension.

TABLES 3 - 4a,b,c

Tables 3-4a,b,c present the 2SRI estimates. Table 3 displays the first-stage estimates of equation (6). Tables 4a-c report, for each dependent variable, the second-stage Negative Binomial estimates for the model in equation (5) where the residuals from the first-stage (Response, Generalized, Deviance for the Probit model; Response, Standardised Pearson for the Logit model; linear response for LPM) are included, together with the regressors of the baseline model. The second-stage standard errors are bootstrapped in order to account for the inclusion of a generated regressor from first-stage estimates.

The results from the first-stage estimates are consistent across specifications in terms of signs and significance levels. Most importantly, the two instrumental variables come out to be significant predictors of the probability of opening hours being extended, and the direction is in line with expectations. The larger the number of GPs in the group, the larger the probability of opting for the extension. Similarly, having worked in association for a longer period, increased the probability that GPs would have agreed to extend opening hours. The $\chi^{2}$-test on the IV relevance for the Probit and Logit estimates fails to reject the null hypothesis that the instruments are jointly relevant. Similarly, the standard $F$-test on the joint relevance of the instruments in the LPM specification is well above the standard threshold of 10 (Staiger and Stock, 1997), which indicates that the instruments are jointly relevant and good predictors of the extension. Overall, the estimates of the reduced-form model for the extension provide evidence in support of our choice of IVs.

Provided that the instruments are valid, the inclusion of the first stage residuals ensures that the estimates account for the potential endogeneity of the participation dummy. When dealing with those cases associated to avoidable ED attendances (white codes and potentially inappropriate admissions), the estimates of the coefficient $\rho$ are not significant and indicate that the participation dummy can be safely treated as exogenous. Such evidence is fairly robust in the present context, as the result holds true regardless of the specification of the first-stage equation and of the definition of residuals adopted. The indications are less clear-cut when we consider total admissions. In this latter case, our estimates highlight a possible endogeneity of program participation, in particular when the first stage equation is estimated by Probit MLE. 
As in the baseline model, also in the 2SRI estimates the participation coefficient is always negative and its magnitude is larger when for white codes and potentially inappropriate admissions compared to total visits. Moreover, in the few cases where the first stage residuals come out significant, all referring to total admissions, the extension dummy is significant. As for potentially inappropriate admissions, also the 2SRI estimates confirm that the extension of practice opening significantly lowers the use of ED wards. For white codes, the inclusion of the first stage residuals weakens the significance of the participation dummy, which in most cases is reached at the $10 \%$ level. ${ }^{6}$ With respect to the remaining set of covariates, our estimates provides fairly similar results across the different specifications, and the estimated effects follow the same direction recorded for the estimates of the baseline model presented in Table 2.

Tables 5 reports the estimates for the outcome model in (5) obtained by a GMM estimator which exploits the orthogonality condition in equation (9). Also in this case, the IVs are the size of the group and the number of years.

\section{TABLE 5}

The Hansen's J test for over-identifying restrictions provides information about the joint validity of the moment restrictions imposed. According to the test, we fail to reject the null hypothesis of joint validity of the exclusion restrictions. The GMM estimates for the coefficient of the extended opening are negative and highly significant, in particular when avoidable ED admissions are considered. As for total visits, the coefficient is significant at $10 \%$ level. Likewise, the effects of the covariates are also very similar to the results discussed in the previous cases. Overall, the GMM estimates confirm that greater accessibility to primary care practices, as proxied by the extension of opening hours, can effectively reduce ED attendances. Such evidence is robust to the choice of different IV estimation strategies designed to tackle endogeneity.

\section{Concluding remarks}

Improving accessibility to primary care services has been a recurring headlining topic on the agenda of Italian policymakers in recent years. This is an important target not only nationwide, but also for the EmiliaRomagna region, where increasing efforts have been made to extend the opening hours of GPs working in group practices, in order to ensure an overall daily coverage of up to 12 hours. The main goal of the present work is to assess the impact of these organisational features on hospital ED attendances. Our aim is to gain a better insight into the effectiveness of a policy designed to increase appropriateness in the use of hospital services in general, and emergency care in particular.

\footnotetext{
${ }^{6}$ The only case in which the participation dummy for white codes is not significant at the conventional level occurs when the generalised probit residuals are included.
} 
To this end, we consider different measures of those ED visits not followed by hospitalisation, aggregated at the GP level. We focus in particular on those cases which, according to both urgency and severity criteria, should have been preferably treated in a primary care setting. Given that we deal with count data characterised by over-dispersion, our main estimating models are based on the Negative Binomial specification, although the main results also hold under a Poisson and a linear specification.

We consider a set of potential explanatory variables mainly related to GP, practice and list characteristics. The evidence is remarkably consistent across alternative measures of ED utilisation in terms of sign of the estimated coefficients and their significance level. The results for our baseline specification support the hypothesis that increasing daytime accessibility of the practice permits a reduction in ED utilisation, with a stronger effect for avoidable visits compared to total admissions. In line with the expectations, larger daytime opening of practices discourages the use of EDs of less severe patients relatively more. Finally, given that the program participation is a free choice of GPs' groups, we also implement IV strategies (2SRI and GMM) to test and account for its potential endogeneity. According to our tests, endogeneity does not emerge as a serious empirical concern when the analysis concentrates on the admissions which are more likely to be avoided thanks to improved primary care availability, namely white codes and potentially inappropriate admissions.

\section{References}

Afilalo, J., Marinovich, A., Afilalo M, et al. (2004) Nonurgent emergency department patient characteristics and barriers to primary care. Ac Emerg Med, 11, 1302-10.

Ameri, M., Cremonesi, P. and Montefiori, M. (2011) The Effects of Inappropriate Emergency Department Use. Studi Economici, 105, 123-136.

Armstrong, B., Levesque, O., Perlin, J.B. et al. (2006) Reinventing Veterans Health Administration: focus on primary care. J Healthc Manag, 9, 80-85.

Basu, A. and Manning, W.G. (2009) Issues for the Next Generation of Health Care Cost Analysis. Med Care, 47, s109-14.

Bianco, A., Pileggi, C. and Angelillo, I.F. (2003) Non-urgent visits to a hospital emergency department in Italy. Public Health, 117, 250-55.

Calderòn-Larranaga, A., Carney, L., Soljak, M. et al. (2011) Association of population and primary healthcare factors with hospital admissions rates for chronic obstructive pulmonary disease in England. Thorax, 66, 191-96.

Cameron, A.C. and Trivedi, P.K. (2013) Regression Analysis of Count Data (2 $2^{\text {nd }}$ ed). Econometric Society Monograph No.53, Cambridge University Press.

Carlsen, F., Grytten, J., Kjelvik, J. and Skau, I. (2007) Better primary physician services lead to fewer hospital admissions. Eur J Health Econ, 8,17-24.

Chauhan, M., Bankart, M. J., Labeit, A. and Baker, R. (2012) Characteristics of general practices associated with numbers of elective admissions. J Public Health, 34, 584-590. 
Chan, C.L., Lin, W., Yang, N.P. and Huang, H.T. (2013) The association between the availability of ambulatory care and non-emergency treatment in emergency medicine departments: A comprehensive and nationwide validation. Health Policy, 110, 271-279.

Devlin, R.A. and Sarma, S. (2008) Do physician remuneration schemes matter? The case of Canadian family physicians. J Health Econ, 27, 1168-1181.

Devillanova, C. (2012) Inequalities in access to health care services by the immigrant population: The case of Italy. Working Paper n.166, Econpubblica, Università Bocconi.

Durand, A.C., Gentile, S., Devictor, B. et al. (2011) ED patients: how nonurgent are they? Systematic review of the emergency medicine literature. Am J Emerg Med, 29, 333-345.

Dusheiko, M., Gravelle, H., Jacobs, R. and Smith, P. (2006) The effect of financial incentives on gatekeeping doctors: Evidence from a natural experiment. J Health Econ, 25, 449-478.

Dusheiko, M., Gravelle, H., Martin, S., Rice, N. and Smith, P. (2011) Does better disease management in primary care reduce hospital costs? Evidence from English primary care. J Health Econ, 30, 919-932.

Fantini, M.P., Compagni, A., Rucci, P., Mimmi, S. and Longo, F. (2012) General practitioners' adherence to evidence-based guidelines: A multilevel analysis. Health Care Manag Rev, 37, 67-76.

Fattore, G., Forini, F., Salvatore, D. and Tozzi, V. (2009) Social network analysis in primary care: the impact of interactions on prescribing behaviour. Health Policy, 92, 141-148.

Feachem, R.G., Sekhri, N.K. and White, K.L. (2002) Getting more for their dollar: a comparison of the NHS with California's Kaiser Permanente. BMJ, 324, 135-41.

Fiorentini, G., Iezzi, E., Lippi Bruni, M. and Ugolini, C. (2011) Incentives in primary care and their impact on potentially avoidable hospital admissions. Eur J Health Econ, 12, 297-309.

Fiorentini, G., Lippi Bruni, M. and Ugolini, C. (2013) GPs and hospital expenditures. Shall we keep expenditure containment programs alive? Soc Sci Med, 82, 10-20.

Flores-Mateo, G., Violan-Fors, C., Carrillo-Santisteve, P., Peiro, S. and Argimon, J.M. (2012) Effectiveness of organizational interventions to reduce emergency department utilization: a systematic review. PLoS ONE; 7(5):e35903.

Fortin, B., Jacquemet, N. and Shearer, B.S. (2010) Labour Supply, Work Effort and Contract Choice: Theory and Evidence on Physicians, IZA Discussion Paper n. 5188.

GAO, General Accounting Office (2009) Hospital emergency departments. Publication 09-347, Washington DC, April.

Garrido, M.M., Deb, P., Burgess, J.F. and Penrod, J.D. (2012) Choosing Models for Health Care Cost Analysis: Issues of Nonlinearity and Endogeneity. Health Serv Res,47, 2377-97.

Gourieroux, C., Monfort, A., Renault, E. and Trognon, A. (1987) Generalized residuals. J Econometrics, 34, 5-32.

Grytten, J. and Sorensen, R. (2001) Type of contract and supplier-induced demand for primary physicians in Norway. J Health Econ, 20, 379-393.

Guttman, N., Zimmerman, D.R. and Nelson, M.S. (2003) The many faces of access: reason for medically nonurgent emergency department visits. J Health Polit Polic, 28, 1089-120.

Hansagi, H., Carlsson, B., Olsson, M. and Edhag, O. (1987) Trial of a method of reducing inappropriate demands on a hospital emergency department. Public Health, 10, 99-105.

Harris, M.J., Patel, B. and Bowen, S. (2011) Primary care access and its relationship with emergency department utilisation. Brit J Gen Pract, 61, e787-93.

Hausman, J.A. (1978) Specification Tests in Econometrics. Econometrica, 46, 1251-71. 
Howard, M. and Goertzen, J. (2008) Emergency Department and Walk-in-Clinic use in models of primary care practice with different after-hours accessibility in Ontario. Healthc Policy, 4, 73-88.

Iezzi, E., Lippi Bruni, M. and Ugolini, C. (2014) The role of GP's compensation schemes in diabetes care: Evidence from panel data. J Health Econ, 34, 104-120

Italian Ministry of Health (2010) Cittadini e salute: La soddisfazione degli Italiani per la sanità (in Italian). Quaderni del Ministero della Salute, n.5.

Jimenez-Rubio, D. and Hernandez-Quevedo, C. (2011) Inequalities in the use of health services between immigrants and the native population in Spain: what is driving the differences? Eur J Health Econ, 12, $17-$ 28.

Lang, T., David, A., Diakitè, B., Agay, E., et al. (1996) Non-urgent care in the hospital medical emergency department in France: how much and which health needs does it reflect? J Epidemiol Community Health, 50, 45-62.

Lee, A., Lau, F.L., Hazlett, C.B. et al. (2000) Factors associated with non-urgent utilization of Accident and Emergency services: a case-control study in Hong Kong. Soc Sci Med, 51, 1075-85.

Lega, F. and Mengoni, A. (2008) Why non-urgent patients choose emergency over primary care services? Empirical evidence and managerial implications. Health Policy, 88, 326-38.

Levaggi, R. and Montefiori, M. (2013) Definition of a prospective payment system to reimburse emergency department. BMC Health Serv Res, 13, 409.

Lo Scalzo, A., Donatini, A., Orzella, L. et al. (2009) Health System in Transition-Italy. European Observatory on Health Systems and Policies, 11 (6).

Lowe, R.A., Localio, A.R., Schwarx, D.F. et al. (2005) Association between primary care practice characteristics and emergency department use in a Medicaid managed care organization. Med Care, 3, 792800.

McCormick, B. and Nicodemo, C. (2014) The supply of Gatekeeper GPs, access and hospital admissions.

Presented at the EEA- ESEM conference, Toulouse.

McCusker, J., Roberge, D., Lévesque, J.F. et al (2010) Emergency Department visits and primary care among adults with chronic conditions. Med Care, 48, 972-80.

McGraig, L. and Burt, C.W. (2006) National hospital ambulatory medical care survey: 2004 emergency department summary. Advances in Data, 372: 1-5.

Moll van Charante, E.P., ter Riet, G. and Bindels, P. (2008) Self-referrals to the A\&E department during outof-hours: patients' motive and characteristics. Pat Educ Couns, 70, 256-65.

Moll van Charante, E.P., van Steewikj-Opdam, P. and Bindels, P. (2007) Out-of-hours demand for GP care and emergency services: patients'choice and referrals by general practitioners and ambulance services. $B M C$ Fam Pract, 8, 46.

Mullahy, J. (1997) Instrumental-Variable Estimation Of Count Data Models: Applications To Models Of Cigarette Smoking Behavior. Rev Econ Stat, 79, 586-93.

OECD (2014) OECD Health Statistics 2014. Permanent URL: http://www.oecd.org/health/healthdata.

Pines, J.M. et al. (22 authors) (2011) International perspectives on emergency department crowding. Acad Emerg Med, 18, 1358-70.

Pizer, S.D. (2009) An intuitive review of methods for observational studies of comparative effectiveness. Health Serv Outcome Res Methodol, 9, 54-68.

Propper, C., Croxson, B. and Shearer, A. (2002) Waiting times for hospital admissions: the impact of GP fundholding. J Health Econ, 21, 227-252. 
Puig-Junoy, J., Saez, M. and Martìnez-Garcìa, E. (1998) Why do patients prefer hospital emergency visits? A nested multinomial logit analysis for patient-initiated contacts. Health Care Manage Science, 1, 39-52.

Rivers, D. and Vuong, Q. (1988) Limited Information Estimators and Exogeneity Tests for Simultaneous Probit Models. J Econometrics, 39, 347-66.

Roberts, E. and Mays, N. (1998) Can primary care and community-based models of emergency care substitute for the hospital A\&E department? Health Policy, 44, 191-214.

Saxena, S., George, J., Barber, J. et al. (2006) Association of population and practice factors with potentially avoidable admission rates for chronic diseases in London. J Roy Soc Med, 99, 81-89.

Sempere-Selva, T., Peirò, S., Sendra-Pina, P., Martinez-Espin, C. and Lòpez-Aguilera, I. (2001) Inappropriate use of an accident and emergency department: magnitude, associate factors and reasons. Ann Emerg Med, 37, 568-79.

Shah, N.M., Shah, M.A. and Behbehani, J. (1996) Predictors of non-urgent utilization of hospital emergency services in Kuwait. Soc Sci Med, 42, 1313-23.

Shaw, S.E. and Meads, G. (2012) Extending primary care: potential learning from Italy. Primary Health Care Res \& Development, 13, 289-93.

Smith, R.J. and Blundell, R.W. (1986) An Exogeneity Test for a Simultaneous Equation Tobit Model with an Application to Labor Supply. Econometrica, 54, 679-85.

Staiger, D. and Stock, J.H. (1997) Instrumental Variables Regression with Weak Instruments. Econometrica, 65, 557-86

Terza, J.V. (2006) Estimation of policy effects using parametric nonlinear models: a contextual critique of the generalized method of moments. Health Serv Outcomes Res Method, 6, 177-198.

Terza, J.V., Bradford, W.D. and Dismuke, C.E. (2008) The use of linear instrumental variables methods in health services research and health economics: a cautionary note. Health Ser Res, 43, 1102-20.

Terza, J.V., Basu, A. and Rathouz, P.J. (2008) Two-stage residual inclusion estimation: Addressing endogeneity in health econometric modelling. J Health Econ, 27, 531-43.

Terza, J.V. (2014) Instrumental Variables: Methods. Encyclopedia of Health Economics, 2: 67-71.

Thompson, C., Hayhurst, C. and Boyle, A. (2010) How have changes to out-of-hours primary care services since 2004 affected emergency department attendances at a UK District General Hospital? A longitudinal study. Emergen Med, 27, 22-25.

Trivedi, P.K. (2014) Models of count data. Encyclopedia of Health Economics, 2: 306-11.

Windmeijer, F.A.G. and Santos Silva, J.M.C. (1997) Endogeneity in count data models: an application to demand for health care. J Appl Econom, 12, 281-94.

Wooldridge, J.M. (1997) Quasi-likelihood methods for count data, in Pesaran H, Schmidt P, eds Handbook of Applied Econometrics. Volume II: Microeconometrics, Blackwell Publishers Ltd, Malden, MA.

Wooldridge, J.M. (2010) Econometric analysis of cross section and panel data (2 ${ }^{\text {nd }}$ ed), MIT Press, Cambridge, MA. 
Table 1. Descriptive statistics for the variables included in the model

\begin{tabular}{|c|c|c|c|c|c|c|c|}
\hline \multirow[b]{2}{*}{ Dependent Variables } & \multicolumn{2}{|c|}{ WHOLE SAMPLE (1082 GPs) } & \multicolumn{2}{|c|}{ NO EXTENSION (760 GPs) } & \multicolumn{2}{|c|}{ EXTENSION (322 GPs) } & \multirow[t]{2}{*}{ t_pval } \\
\hline & Mean & Std. Dev. & Mean & Std. Dev. & Mean & Std. Dev. & \\
\hline White codes & 71.354 & 59.267 & 79.208 & 64.805 & 52.817 & 37.524 & 0.000 \\
\hline Potentially inappropriate visits & 150.836 & 82.362 & 163.491 & 85.090 & 120.969 & 66.713 & 0.000 \\
\hline Total ED visits & 377.362 & 130.118 & 389.338 & 133.624 & 349.096 & 116.860 & 0.000 \\
\hline \multicolumn{8}{|l|}{ Control variables } \\
\hline Extension $10-12$ & 0.298 & 0.457 & 0 & 0 & 1 & 0 & \\
\hline Male GP & 0.734 & 0.442 & 0.718 & 0.450 & 0.770 & 0.421 & 0.071 \\
\hline GP seniority & 21.317 & 8.252 & 21.087 & 8.310 & 21.860 & 8.100 & 0.155 \\
\hline Mountainous area & 0.284 & 0.451 & 0.313 & 0.464 & 0.214 & 0.411 & 0.001 \\
\hline Nursing staff & 0.245 & 0.430 & 0.176 & 0.381 & 0.407 & 0.492 & 0.000 \\
\hline List avg age & 50.961 & 3.386 & 51.138 & 3.380 & 50.543 & 3.368 & 0.008 \\
\hline Foreign patients & 0.069 & 0.061 & 0.068 & 0.057 & 0.070 & 0.069 & 0.718 \\
\hline Male patients & 0.478 & 0.039 & 0.475 & 0.039 & 0.484 & 0.038 & 0.000 \\
\hline Previous hosp. & 237.318 & 70.473 & 239.415 & 71.273 & 232.370 & 68.403 & 0.127 \\
\hline Distance & 5.981 & 6.055 & 6.101 & 6.358 & 5.698 & 5.270 & 0.281 \\
\hline List size & $1,265.913$ & 325.008 & $1,262.326$ & 322.462 & $1,274.379$ & 331.294 & 0.582 \\
\hline \multicolumn{8}{|l|}{ Instrumental variables } \\
\hline GPs in the group & 4.723 & 1.760 & 4.420 & 1.467 & 5.438 & 2.148 & 0.000 \\
\hline Years in group & 7.795 & 4.277 & 7.531 & 4.156 & 8.418 & 4.495 & 0.003 \\
\hline
\end{tabular}


Table 2 - ED visits for GP, year 2009 *

\begin{tabular}{|c|c|c|c|c|c|c|c|c|c|}
\hline & NegBin & Poisson & $\mathrm{OLS}^{+}$ & NegBin & Poisson & $\mathrm{OLS}^{+}$ & NegBin & Poisson & $\mathrm{OLS}^{+}$ \\
\hline DEP VAR & \multicolumn{3}{|c|}{ White codes } & \multicolumn{3}{|c|}{ Potentially inappropriate visits } & \multicolumn{3}{|c|}{ "Total ED visits } \\
\hline Extension $10-12$ & $\begin{array}{c}-0.0688 \\
(0.034) \\
0.042\end{array}$ & $\begin{array}{c}-0.1147 \\
(0.039) \\
0.004\end{array}$ & $\begin{array}{c}-0.0078 \\
(0.002) \\
0.000\end{array}$ & $\begin{array}{c}-0.0881 \\
(0.025) \\
0.001\end{array}$ & $\begin{array}{c}-0.1018 \\
(0.026) \\
0.000\end{array}$ & $\begin{array}{c}-0.0127 \\
(0.003) \\
0.000\end{array}$ & $\begin{array}{c}-0.0321 \\
(0.017) \\
0.053\end{array}$ & $\begin{array}{c}-0.0433 \\
(0.016) \\
0.006\end{array}$ & $\begin{array}{c}-0.0131 \\
(0.005) \\
0.006\end{array}$ \\
\hline Male GP & $\begin{array}{c}-0.0553 \\
(0.044) \\
0.213\end{array}$ & $\begin{array}{c}-0.1072 \\
(0.051) \\
0.036\end{array}$ & $\begin{array}{c}-0.0044 \\
(0.003) \\
0.176\end{array}$ & $\begin{array}{c}-0.0426 \\
(0.036) \\
0.231\end{array}$ & $\begin{array}{c}-0.0650 \\
(0.035) \\
0.061\end{array}$ & $\begin{array}{c}-0.0034 \\
(0.005) \\
0.501\end{array}$ & $\begin{array}{c}-0.0538 \\
(0.023) \\
0.019\end{array}$ & $\begin{array}{c}-0.0631 \\
(0.021) \\
0.002\end{array}$ & $\begin{array}{c}-0.0098 \\
(0.008) \\
0.194\end{array}$ \\
\hline GP seniority & $\begin{array}{c}-0.0063 \\
(0.002) \\
0.000\end{array}$ & $\begin{array}{c}-0.0073 \\
(0.002) \\
0.001\end{array}$ & $\begin{array}{c}-0.0004 \\
(0.000) \\
0.001\end{array}$ & $\begin{array}{c}-0.0055 \\
(0.001) \\
0.000\end{array}$ & $\begin{array}{c}-0.0060 \\
(0.001) \\
0.000\end{array}$ & $\begin{array}{c}-0.0008 \\
(0.000) \\
0.000\end{array}$ & $\begin{array}{c}-0.0040 \\
(0.001) \\
0.000\end{array}$ & $\begin{array}{c}-0.0039 \\
(0.001) \\
0.000\end{array}$ & $\begin{array}{c}-0.0013 \\
(0.000) \\
0.000\end{array}$ \\
\hline Mountainous area & $\begin{array}{c}0.2366 \\
(0.037) \\
0.000\end{array}$ & $\begin{array}{c}0.2721 \\
(0.040) \\
0.000\end{array}$ & $\begin{array}{c}0.0185 \\
(0.003) \\
0.000\end{array}$ & $\begin{array}{c}0.0928 \\
(0.029) \\
0.001\end{array}$ & $\begin{array}{c}0.0828 \\
(0.028) \\
0.004\end{array}$ & $\begin{array}{c}0.0116 \\
(0.004) \\
0.003\end{array}$ & $\begin{array}{c}0.0069 \\
(0.019) \\
0.712\end{array}$ & $\begin{array}{c}-0.0052 \\
(0.018) \\
0.768\end{array}$ & $\begin{array}{c}-0.0019 \\
(0.006) \\
0.734\end{array}$ \\
\hline Nursing staff & $\begin{array}{c}-0.1779 \\
(0.038) \\
0.000\end{array}$ & $\begin{array}{c}-0.2210 \\
(0.041) \\
0.000\end{array}$ & $\begin{array}{c}-0.0108 \\
(0.002) \\
0.000\end{array}$ & $\begin{array}{c}-0.1341 \\
(0.027) \\
0.000\end{array}$ & $\begin{array}{c}-0.1452 \\
(0.027) \\
0.000\end{array}$ & $\begin{array}{c}-0.0151 \\
(0.003) \\
0.000\end{array}$ & $\begin{array}{c}-0.0577 \\
(0.018) \\
0.001\end{array}$ & $\begin{array}{c}-0.0589 \\
(0.017) \\
0.001\end{array}$ & $\begin{array}{c}-0.0159 \\
(0.005) \\
0.001\end{array}$ \\
\hline List avg age & $\begin{array}{c}-0.0314 \\
(0.006) \\
0.000\end{array}$ & $\begin{array}{c}-0.0242 \\
(0.007) \\
0.000\end{array}$ & $\begin{array}{c}-0.0013 \\
(0.000) \\
0.002\end{array}$ & $\begin{array}{c}-0.0207 \\
(0.004) \\
0.000\end{array}$ & $\begin{array}{c}-0.0217 \\
(0.004) \\
0.000\end{array}$ & $\begin{array}{c}-0.0027 \\
(0.001) \\
0.000\end{array}$ & $\begin{array}{c}-0.0045 \\
(0.003) \\
0.120\end{array}$ & $\begin{array}{c}-0.0049 \\
(0.003) \\
0.063\end{array}$ & $\begin{array}{c}-0.0018 \\
(0.001) \\
0.065\end{array}$ \\
\hline Foreign patients (\% list) & $\begin{array}{c}1.0371 \\
(0.327) \\
0.002\end{array}$ & $\begin{array}{c}0.8404 \\
(0.338) \\
0.013\end{array}$ & $\begin{array}{c}0.0687 \\
(0.025) \\
0.007\end{array}$ & $\begin{array}{c}0.9180 \\
(0.247) \\
0.000\end{array}$ & $\begin{array}{c}0.6971 \\
(0.231) \\
0.003\end{array}$ & $\begin{array}{c}0.1188 \\
(0.035) \\
0.001\end{array}$ & $\begin{array}{c}0.9172 \\
(0.175) \\
0.000\end{array}$ & $\begin{array}{c}0.7743 \\
(0.163) \\
0.000\end{array}$ & $\begin{array}{c}0.3017 \\
(0.057) \\
0.000\end{array}$ \\
\hline Male patients (\% list) & $\begin{array}{c}1.8993 \\
(0.510) \\
0.000\end{array}$ & $\begin{array}{c}2.5808 \\
(0.608) \\
0.000\end{array}$ & $\begin{array}{c}0.1337 \\
(0.043) \\
0.002\end{array}$ & $\begin{array}{c}1.1043 \\
(0.442) \\
0.012\end{array}$ & $\begin{array}{c}1.5335 \\
(0.421) \\
0.000\end{array}$ & $\begin{array}{c}0.1519 \\
(0.074) \\
0.041\end{array}$ & $\begin{array}{c}0.7372 \\
(0.297) \\
0.013\end{array}$ & $\begin{array}{c}0.8956 \\
(0.264) \\
0.001\end{array}$ & $\begin{array}{c}0.1851 \\
(0.109) \\
0.091\end{array}$ \\
\hline Previous hosp. & $\begin{array}{c}0.0001 \\
(0.000) \\
0.608\end{array}$ & $\begin{array}{c}0.0003 \\
(0.000) \\
0.401\end{array}$ & $\begin{array}{c}0.0000 \\
(0.000) \\
0.475\end{array}$ & $\begin{array}{c}-0.0002 \\
(0.000) \\
0.195\end{array}$ & $\begin{array}{c}-0.0000 \\
(0.000) \\
0.813\end{array}$ & $\begin{array}{c}-0.0000 \\
(0.000) \\
0.388\end{array}$ & $\begin{array}{c}-0.0002 \\
(0.000) \\
0.117\end{array}$ & $\begin{array}{c}-0.0001 \\
(0.000) \\
0.530\end{array}$ & $\begin{array}{c}-0.0001 \\
(0.000) \\
0.150\end{array}$ \\
\hline Distance & $\begin{array}{c}-0.0245 \\
(0.002) \\
0.000\end{array}$ & $\begin{array}{c}-0.0235 \\
(0.003) \\
0.000\end{array}$ & $\begin{array}{c}-0.0013 \\
(0.000) \\
0.000\end{array}$ & $\begin{array}{c}-0.0219 \\
(0.002) \\
0.000\end{array}$ & $\begin{array}{c}-0.0205 \\
(0.002) \\
0.000\end{array}$ & $\begin{array}{c}-0.0022 \\
(0.000) \\
0.000\end{array}$ & $\begin{array}{c}-0.0150 \\
(0.002) \\
0.000\end{array}$ & $\begin{array}{c}-0.0141 \\
(0.002) \\
0.000\end{array}$ & $\begin{array}{c}-0.0036 \\
(0.000) \\
0.000\end{array}$ \\
\hline Ln(List size) & $\begin{array}{c}-2.4341 \\
(0.353) \\
0.000 \\
\text { offset }\end{array}$ & $\begin{array}{c}-3.0877 \\
(0.412) \\
0.000 \\
\text { offset }\end{array}$ & $\begin{array}{c}0.0493 \\
(0.026) \\
0.054\end{array}$ & $\begin{array}{c}-1.3854 \\
(0.304) \\
0.000 \\
\text { offset }\end{array}$ & $\begin{array}{c}-1.5488 \\
(0.284) \\
0.000 \\
\text { offset }\end{array}$ & $\begin{array}{c}0.2101 \\
(0.047) \\
0.000\end{array}$ & $\begin{array}{c}-1.0212 \\
(0.191) \\
0.000 \\
\text { offset }\end{array}$ & $\begin{array}{c}-1.0943 \\
(0.168) \\
0.000 \\
\text { offset }\end{array}$ & $\begin{array}{c}0.3905 \\
(0.069) \\
0.000\end{array}$ \\
\hline $\begin{array}{l}\text { Area effects } \\
\text { Alpha }\end{array}$ & $\begin{array}{c}\text { yes } \\
-1.5697 \\
(0.047) \\
0.000\end{array}$ & yes & yes & $\begin{array}{c}\text { yes } \\
-2.2182 \\
(0.046) \\
0.000\end{array}$ & yes & yes & $\begin{array}{c}\text { yes } \\
-3.0133 \\
(0.068) \\
0.000\end{array}$ & yes & yes \\
\hline Observations & 1,082 & 1,082 & 1,082 & 1,082 & 1,082 & 1,082 & 1,082 & 1,082 & 1,082 \\
\hline
\end{tabular}

*Standard Error in parenthesis, $p$-value in italic ${ }^{+}$The dependent variable for the OLS estimate is the ratio $y_{i} /$ listsize. 
Table 3 - Two-stage residual inclusion estimates: FIRST STAGE*

\begin{tabular}{|c|c|c|c|}
\hline FIRST STAGE & PROBIT & LOGIT & LPM \\
\hline VARIABLES & Extension 10-12 & Extension 10-12 & Extension 10-12 \\
\hline \multirow[t]{3}{*}{ GPs in the group } & 0.2533 & 0.4340 & 0.0725 \\
\hline & $(0.026)$ & $(0.046)$ & $(0.007)$ \\
\hline & 0.000 & 0.000 & 0.000 \\
\hline \multirow[t]{3}{*}{ Years in group } & 0.0401 & 0.0702 & 0.0087 \\
\hline & $(0.012)$ & $(0.021)$ & $(0.003)$ \\
\hline & 0.001 & 0.001 & 0.005 \\
\hline \multirow[t]{3}{*}{ Male GP } & -0.2351 & -0.3686 & -0.0484 \\
\hline & (0.149) & $(0.265)$ & $(0.040)$ \\
\hline & 0.114 & 0.164 & 0.231 \\
\hline \multirow[t]{3}{*}{ GP seniority } & -0.0049 & -0.0071 & -0.0011 \\
\hline & $(0.006)$ & $(0.011)$ & $(0.002)$ \\
\hline & 0.437 & 0.520 & 0.500 \\
\hline \multirow[t]{3}{*}{ Mountainous area } & 0.0928 & 0.1755 & 0.0347 \\
\hline & (0.109) & (0.190) & $(0.029)$ \\
\hline & 0.393 & 0.357 & 0.228 \\
\hline \multirow[t]{3}{*}{ Nursing staff } & 0.2691 & 0.4491 & 0.0806 \\
\hline & $(0.107)$ & $(0.180)$ & $(0.035)$ \\
\hline & 0.012 & 0.013 & 0.023 \\
\hline \multirow[t]{3}{*}{ List avg age } & -0.0469 & -0.0804 & -0.0132 \\
\hline & $(0.017)$ & $(0.029)$ & $(0.004)$ \\
\hline & 0.005 & 0.006 & 0.003 \\
\hline \multirow[t]{3}{*}{ Foreign patients (\% list) } & -2.6365 & -4.8079 & -0.7328 \\
\hline & (1.049) & (1.819) & $(0.288)$ \\
\hline & 0.012 & 0.008 & 0.011 \\
\hline \multirow[t]{3}{*}{ Male patients (\% list) } & 7.1951 & 12.0981 & 1.7778 \\
\hline & $(1.671)$ & $(2.994)$ & $(0.428)$ \\
\hline & 0.000 & 0.000 & 0.000 \\
\hline \multirow[t]{3}{*}{ Previous hosp. } & -0.0014 & -0.0026 & -0.0003 \\
\hline & $(0.001)$ & $(0.001)$ & $(0.000)$ \\
\hline & 0.066 & 0.042 & 0.086 \\
\hline \multirow[t]{3}{*}{ Distance } & -0.0227 & -0.0420 & -0.0059 \\
\hline & (0.009) & $(0.015)$ & $(0.002)$ \\
\hline & 0.010 & 0.005 & 0.004 \\
\hline \multirow[t]{3}{*}{ Constant } & -2.3579 & -3.9020 & -0.1054 \\
\hline & (1.089) & $(1.905)$ & $(0.287)$ \\
\hline & 0.030 & 0.041 & 0.714 \\
\hline Area effects & yes & yes & yes \\
\hline Observations & 1,082 & 1,082 & 1,082 \\
\hline R-squared & & & 0.235 \\
\hline Test on IV relevance & $\chi^{2}=99.58(p=0.000)$ & $\chi^{2}=94.66(p=0.000)$ & $F=57.65(p=0.000)$ \\
\hline
\end{tabular}

*Standard Error in parenthesis, $p$-value in italics 
Table 4a-2RSI: SECOND STAGE for White Code visits*

\begin{tabular}{|c|c|c|c|c|c|c|}
\hline SECOND STAGE NEGBIN & PROBIT Res & PROBITGen Res & PROBIT Dev Res & LOGIT Res & LOGIT Std Pearson & LPM Res \\
\hline \multirow[t]{3}{*}{ Extension $10-12$} & -0.1790 & -0.1416 & -0.2184 & -0.1724 & -0.1269 & -0.2323 \\
\hline & $(0.100)$ & $(0.106)$ & $(0.135)$ & (0.099) & $(0.075)$ & $(0.115)$ \\
\hline & 0.072 & 0.181 & 0.105 & 0.082 & 0.092 & 0.043 \\
\hline \multirow[t]{3}{*}{ Male GP } & -0.0635 & -0.0606 & -0.0643 & -0.0623 & -0.0579 & -0.0667 \\
\hline & $(0.047)$ & $(0.048)$ & $(0.044)$ & $(0.048)$ & $(0.044)$ & $(0.048)$ \\
\hline & 0.176 & 0.207 & 0.146 & 0.198 & 0.190 & 0.162 \\
\hline \multirow[t]{3}{*}{ GP seniority } & -0.0062 & -0.0062 & -0.0062 & -0.0062 & -0.0062 & -0.0061 \\
\hline & $(0.002)$ & $(0.002)$ & $(0.002)$ & $(0.002)$ & $(0.002)$ & $(0.002)$ \\
\hline & 0.000 & 0.000 & 0.001 & 0.001 & 0.000 & 0.001 \\
\hline \multirow[t]{3}{*}{ Mountainous area } & 0.2347 & 0.2357 & 0.2340 & 0.2351 & 0.2358 & 0.2331 \\
\hline & $(0.034)$ & $(0.036)$ & $(0.036)$ & $(0.035)$ & $(0.041)$ & $(0.042)$ \\
\hline & 0.000 & 0.000 & 0.000 & 0.000 & 0.000 & 0.000 \\
\hline \multirow[t]{3}{*}{ Nursing staff } & -0.1630 & -0.1682 & -0.1621 & -0.1641 & -0.1706 & -0.1556 \\
\hline & $(0.039)$ & $(0.036)$ & $(0.041)$ & $(0.033)$ & $(0.035)$ & $(0.040)$ \\
\hline & 0.000 & 0.000 & 0.000 & 0.000 & 0.000 & 0.000 \\
\hline \multirow[t]{3}{*}{ List avg age } & -0.0326 & -0.0322 & -0.0327 & -0.0325 & -0.0321 & -0.0332 \\
\hline & $(0.006)$ & $(0.006)$ & $(0.006)$ & $(0.005)$ & $(0.006)$ & $(0.006)$ \\
\hline & 0.000 & 0.000 & 0.000 & 0.000 & 0.000 & 0.000 \\
\hline \multirow[t]{3}{*}{ Foreign patients (\% list) } & 0.9671 & 0.9866 & 0.9512 & 0.9668 & 0.9848 & 0.9219 \\
\hline & $(0.359)$ & $(0.365)$ & $(0.325)$ & $(0.345)$ & $(0.358)$ & $(0.360)$ \\
\hline & 0.007 & 0.007 & 0.003 & 0.005 & 0.006 & 0.010 \\
\hline \multirow[t]{3}{*}{ Male patients (\% list) } & 2.1259 & 2.0474 & 2.1521 & 2.1060 & 2.0013 & 2.2324 \\
\hline & $(0.561)$ & $(0.598)$ & $(0.546)$ & $(0.592)$ & $(0.511)$ & $(0.573)$ \\
\hline & 0.000 & 0.001 & 0.000 & 0.000 & 0.000 & 0.000 \\
\hline \multirow[t]{3}{*}{ Previous hosp. } & 0.0001 & 0.0001 & 0.0001 & 0.0001 & 0.0001 & 0.0001 \\
\hline & $(0.000)$ & $(0.000)$ & $(0.000)$ & $(0.000)$ & $(0.000)$ & $(0.000)$ \\
\hline & 0.734 & 0.689 & 0.757 & 0.720 & 0.713 & 0.803 \\
\hline \multirow[t]{3}{*}{ Distance } & -0.0253 & -0.0250 & -0.0254 & -0.0253 & -0.0250 & -0.0257 \\
\hline & $(0.002)$ & $(0.002)$ & $(0.002)$ & $(0.002)$ & $(0.002)$ & $(0.003)$ \\
\hline & 0.000 & 0.000 & 0.000 & 0.000 & 0.000 & 0.000 \\
\hline \multirow[t]{3}{*}{ First-stage residuals } & -0.1239 & 0.0476 & 0.0674 & -0.1168 & 0.0267 & 0.1817 \\
\hline & (0.103) & $(0.065)$ & $(0.058)$ & $(0.105)$ & $(0.033)$ & (0.118) \\
\hline & 0.230 & 0.464 & 0.242 & 0.265 & 0.424 & 0.125 \\
\hline \multirow[t]{3}{*}{ Constant } & -2.4345 & -2.4332 & -2.4179 & -2.4314 & -2.4240 & -2.4316 \\
\hline & $(0.322)$ & $(0.346)$ & $(0.384)$ & $(0.344)$ & $(0.377)$ & $(0.378)$ \\
\hline & 0.000 & 0.000 & 0.000 & 0.000 & 0.000 & 0.000 \\
\hline Ln List_size & offset & offset & offset & offset & offset & offset \\
\hline Area effects & YES & YES & YES & YES & YES & YES \\
\hline \multirow{3}{*}{ Alpha } & -1.5706 & -1.5701 & -1.5708 & -1.5705 & -1.5702 & -1.5718 \\
\hline & $(0.048)$ & $(0.050)$ & $(0.049)$ & $(0.046)$ & $(0.049)$ & $(0.050)$ \\
\hline & 0.000 & 0.000 & 0.000 & 0.000 & 0.000 & 0.000 \\
\hline Observations & 1,082 & 1,082 & 1,082 & 1,082 & 1,082 & 1,082 \\
\hline
\end{tabular}

\footnotetext{
* Standard Error in parenthesis, $p$-value in italics
} 
Table 4b - 2RSI: SECOND STAGE for Potentially Inappropriate visits*

\begin{tabular}{|c|c|c|c|c|c|c|}
\hline SECOND STAGE NEGBIN & PROBIT Res & PROBIT Gen Res & PROBIT Dev Res & LOGIT Res & LOGIT Std Pearson & LPM Res \\
\hline \multirow[t]{3}{*}{ Extension $10-12$} & -0.1853 & -0.1547 & -0.1923 & -0.1815 & -0.1296 & -0.1700 \\
\hline & $(0.081)$ & $(0.074)$ & $(0.093)$ & $(0.075)$ & $(0.060)$ & $(0.087)$ \\
\hline & 0.023 & 0.036 & 0.038 & 0.016 & 0.031 & 0.051 \\
\hline \multirow[t]{3}{*}{ Male GP } & -0.0494 & -0.0470 & -0.0485 & -0.0485 & -0.0443 & -0.0478 \\
\hline & $(0.036)$ & $(0.037)$ & $(0.039)$ & $(0.037)$ & $(0.032)$ & $(0.035)$ \\
\hline & 0.164 & 0.205 & 0.211 & 0.185 & 0.169 & 0.173 \\
\hline \multirow[t]{3}{*}{ GP seniority } & -0.0054 & -0.0055 & -0.0054 & -0.0054 & -0.0055 & -0.0054 \\
\hline & $(0.001)$ & $(0.001)$ & $(0.001)$ & $(0.002)$ & $(0.001)$ & $(0.001)$ \\
\hline & 0.000 & 0.000 & 0.000 & 0.000 & 0.000 & 0.000 \\
\hline \multirow[t]{3}{*}{ Mountainous area } & 0.0927 & 0.0930 & 0.0924 & 0.0930 & 0.0930 & 0.0924 \\
\hline & (0.029) & (0.029) & (0.029) & $(0.031)$ & $(0.031)$ & $(0.032)$ \\
\hline & 0.001 & 0.001 & 0.001 & 0.003 & 0.002 & 0.004 \\
\hline \multirow[t]{3}{*}{ Nursing staff } & -0.1209 & -0.1252 & -0.1229 & -0.1216 & -0.1288 & -0.1229 \\
\hline & $(0.030)$ & $(0.030)$ & $(0.030)$ & $(0.029)$ & $(0.029)$ & $(0.030)$ \\
\hline & 0.000 & 0.000 & 0.000 & 0.000 & 0.000 & 0.000 \\
\hline \multirow[t]{3}{*}{ List avg age } & -0.0218 & -0.0214 & -0.0216 & -0.0217 & -0.0212 & -0.0216 \\
\hline & $(0.005)$ & $(0.005)$ & $(0.004)$ & $(0.004)$ & $(0.004)$ & $(0.005)$ \\
\hline & 0.000 & 0.000 & 0.000 & 0.000 & 0.000 & 0.000 \\
\hline \multirow[t]{3}{*}{ Foreign patients (\% list) } & 0.8537 & 0.8711 & 0.8573 & 0.8521 & 0.8816 & 0.8598 \\
\hline & $(0.260)$ & $(0.274)$ & $(0.251)$ & $(0.227)$ & $(0.248)$ & $(0.246)$ \\
\hline & 0.001 & 0.001 & 0.001 & 0.000 & 0.000 & 0.000 \\
\hline \multirow[t]{3}{*}{ Male patients (\% list) } & 1.3010 & 1.2355 & 1.2761 & 1.2878 & 1.1751 & 1.2650 \\
\hline & $(0.482)$ & $(0.489)$ & $(0.505)$ & $(0.521)$ & (0.419) & $(0.476)$ \\
\hline & 0.007 & 0.011 & 0.011 & 0.013 & 0.005 & 0.008 \\
\hline \multirow[t]{3}{*}{ Previous hosp. } & -0.0003 & -0.0003 & -0.0003 & -0.0003 & -0.0003 & -0.0003 \\
\hline & $(0.000)$ & $(0.000)$ & $(0.000)$ & $(0.000)$ & $(0.000)$ & $(0.000)$ \\
\hline & 0.123 & 0.155 & 0.130 & 0.129 & 0.148 & 0.147 \\
\hline \multirow[t]{3}{*}{ Distance } & -0.0226 & -0.0223 & -0.0225 & -0.0226 & -0.0222 & -0.0224 \\
\hline & $(0.002)$ & $(0.002)$ & $(0.002)$ & $(0.002)$ & $(0.002)$ & $(0.002)$ \\
\hline & 0.000 & 0.000 & 0.000 & 0.000 & 0.000 & 0.000 \\
\hline \multirow[t]{3}{*}{ First-stage residuals } & -0.1092 & 0.0433 & 0.0469 & -0.1051 & 0.0191 & 0.0909 \\
\hline & $(0.087)$ & $(0.047)$ & $(0.040)$ & $(0.078)$ & $(0.026)$ & (0.091) \\
\hline & 0.211 & 0.355 & 0.247 & 0.179 & 0.466 & 0.319 \\
\hline \multirow[t]{3}{*}{ Constant } & -1.3820 & -1.3811 & -1.3707 & -1.3792 & -1.3762 & -1.3809 \\
\hline & $(0.308)$ & $(0.313)$ & (0.319) & $(0.297)$ & $(0.298)$ & $(0.322)$ \\
\hline & 0.000 & 0.000 & 0.000 & 0.000 & 0.000 & 0.000 \\
\hline Ln List_size & offset & offset & offset & offset & offset & offset \\
\hline Area effects & YES & YES & YES & YES & YES & YES \\
\hline \multirow{3}{*}{ Alpha } & -2.2198 & -2.2189 & -2.2194 & -2.2198 & -2.2187 & -2.2192 \\
\hline & $(0.046)$ & $(0.045)$ & $(0.043)$ & $(0.043)$ & $(0.042)$ & $(0.048)$ \\
\hline & 0.000 & 0.000 & 0.000 & 0.000 & 0.000 & 0.000 \\
\hline Observations & 1,082 & 1,082 & 1,082 & 1,082 & 1,082 & 1,082 \\
\hline
\end{tabular}

\footnotetext{
* Standard Error in parenthesis, $p$-value in italics
} 
Table 4c - 2RSI: SECOND STAGE for Total ED visits*

\begin{tabular}{|c|c|c|c|c|c|c|}
\hline SECOND STAGE NEGBIN & PROBIT Res & PROBIT Gen Res & PROBIT Dev Res & LOGIT Res & LOGIT Std Pearson & LPM Res \\
\hline \multirow[t]{3}{*}{ Extension $10-12$} & -0.1259 & -0.1249 & -0.1276 & -0.1233 & -0.0874 & -0.0816 \\
\hline & $(0.047)$ & $(0.053)$ & $(0.058)$ & $(0.046)$ & $(0.040)$ & $(0.053)$ \\
\hline & 0.008 & 0.019 & 0.027 & 0.007 & 0.028 & 0.123 \\
\hline \multirow[t]{3}{*}{ Male GP } & -0.0603 & -0.0596 & -0.0591 & -0.0595 & -0.0561 & -0.0568 \\
\hline & $(0.021)$ & $(0.023)$ & $(0.021)$ & $(0.022)$ & $(0.024)$ & $(0.026)$ \\
\hline & 0.005 & 0.010 & 0.005 & 0.007 & 0.017 & 0.027 \\
\hline \multirow[t]{3}{*}{ GP seniority } & -0.0039 & -0.0039 & -0.0039 & -0.0039 & -0.0039 & -0.0039 \\
\hline & $(0.001)$ & $(0.001)$ & $(0.001)$ & $(0.001)$ & $(0.001)$ & $(0.001)$ \\
\hline & 0.000 & 0.000 & 0.000 & 0.000 & 0.000 & 0.000 \\
\hline \multirow[t]{3}{*}{ Mountainous area } & 0.0071 & 0.0073 & 0.0069 & 0.0073 & 0.0072 & 0.0070 \\
\hline & $(0.017)$ & (0.019) & $(0.018)$ & $(0.018)$ & $(0.020)$ & (0.019) \\
\hline & 0.672 & 0.701 & 0.706 & 0.676 & 0.716 & 0.717 \\
\hline \multirow[t]{3}{*}{ Nursing staff } & -0.0444 & -0.0447 & -0.0471 & -0.0449 & -0.0503 & -0.0507 \\
\hline & $(0.018)$ & $(0.020)$ & (0.019) & $(0.018)$ & $(0.018)$ & (0.019) \\
\hline & 0.012 & 0.026 & 0.014 & 0.012 & 0.006 & 0.009 \\
\hline \multirow[t]{3}{*}{ List avg age } & -0.0056 & -0.0056 & -0.0054 & -0.0055 & -0.0051 & -0.0051 \\
\hline & $(0.003)$ & $(0.003)$ & $(0.003)$ & $(0.003)$ & $(0.003)$ & $(0.003)$ \\
\hline & 0.059 & 0.052 & 0.090 & 0.089 & 0.087 & 0.101 \\
\hline \multirow[t]{3}{*}{ Foreign patients (\% list) } & 0.8538 & 0.8503 & 0.8606 & 0.8513 & 0.8671 & 0.8818 \\
\hline & $(0.176)$ & $(0.153)$ & $(0.181)$ & $(0.168)$ & (0.169) & $(0.182)$ \\
\hline & 0.000 & 0.000 & 0.000 & 0.000 & 0.000 & 0.000 \\
\hline \multirow[t]{3}{*}{ Male patients (\% list) } & 0.9241 & 0.9166 & 0.8927 & 0.9135 & 0.8321 & 0.8322 \\
\hline & (0.299) & $(0.320)$ & $(0.301)$ & $(0.302)$ & $(0.317)$ & $(0.343)$ \\
\hline & 0.002 & 0.004 & 0.003 & 0.002 & 0.009 & 0.015 \\
\hline \multirow[t]{3}{*}{ Previous hosp. } & -0.0002 & -0.0002 & -0.0002 & -0.0002 & -0.0002 & -0.0002 \\
\hline & $(0.000)$ & $(0.000)$ & $(0.000)$ & $(0.000)$ & $(0.000)$ & $(0.000)$ \\
\hline & 0.068 & 0.037 & 0.079 & 0.092 & 0.083 & 0.082 \\
\hline \multirow[t]{3}{*}{ Distance } & -0.0156 & -0.0156 & -0.0155 & -0.0156 & -0.0154 & -0.0153 \\
\hline & $(0.002)$ & $(0.002)$ & $(0.002)$ & $(0.002)$ & $(0.002)$ & $(0.002)$ \\
\hline & 0.000 & 0.000 & 0.000 & 0.000 & 0.000 & 0.000 \\
\hline \multirow[t]{3}{*}{ First-stage residuals } & -0.1048 & 0.0600 & 0.0428 & -0.1021 & 0.0253 & 0.0547 \\
\hline & $(0.051)$ & $(0.033)$ & $(0.025)$ & $(0.051)$ & $(0.016)$ & (0.054) \\
\hline & 0.040 & 0.071 & 0.084 & 0.043 & 0.122 & 0.310 \\
\hline \multirow[t]{3}{*}{ Constant } & -1.0153 & -1.0125 & -1.0061 & -1.0127 & -1.0095 & -1.0167 \\
\hline & $(0.184)$ & $(0.195)$ & $(0.208)$ & $(0.207)$ & (0.199) & (0.199) \\
\hline & 0.000 & 0.000 & 0.000 & 0.000 & 0.000 & 0.000 \\
\hline Ln List_size & offset & offset & offset & offset & offset & offset \\
\hline Area effects & YES & YES & YES & YES & YES & YES \\
\hline \multirow{3}{*}{ Alpha } & -3.0170 & -3.0167 & -3.0157 & -3.0169 & -3.0154 & -3.0142 \\
\hline & $(0.070)$ & $(0.061)$ & $(0.068)$ & $(0.069)$ & $(0.073)$ & $(0.065)$ \\
\hline & 0.000 & 0.000 & 0.000 & 0.000 & 0.000 & 0.000 \\
\hline Observations & 1,082 & 1,082 & 1,082 & 1,082 & 1,082 & 1,082 \\
\hline
\end{tabular}

\footnotetext{
* Standard Error in parenthesis, $p$-value in italics
} 
Table 5 - GMM estimates *

\begin{tabular}{|c|c|c|c|}
\hline DEP. VAR & White codes & Potentially inappropriate visits & Total ED visits \\
\hline \multirow[t]{3}{*}{ Extension 10-12 } & -0.2333 & -0.1777 & -0.0936 \\
\hline & $(0.103)$ & $(0.079)$ & $(0.052)$ \\
\hline & 0.023 & 0.025 & 0.071 \\
\hline \multirow[t]{3}{*}{ Male GP } & -0.0534 & -0.0456 & -0.0550 \\
\hline & $(0.048)$ & $(0.036)$ & $(0.023)$ \\
\hline & 0.262 & 0.206 & 0.016 \\
\hline \multirow[t]{3}{*}{ GP seniority } & -0.0061 & -0.0055 & -0.0041 \\
\hline & $(0.002)$ & $(0.001)$ & $(0.001)$ \\
\hline & 0.001 & 0.000 & 0.000 \\
\hline \multirow[t]{3}{*}{ Mountainous area } & 0.2322 & 0.0957 & 0.0053 \\
\hline & $(0.036)$ & $(0.029)$ & $(0.020)$ \\
\hline & 0.000 & 0.001 & 0.788 \\
\hline \multirow[t]{3}{*}{ Nursing staff } & -0.1581 & -0.1229 & -0.0492 \\
\hline & $(0.035)$ & $(0.030)$ & $(0.018)$ \\
\hline & 0.000 & 0.000 & 0.006 \\
\hline \multirow[t]{3}{*}{ List avg age } & -0.0339 & -0.0216 & -0.0049 \\
\hline & $(0.006)$ & $(0.005)$ & $(0.003)$ \\
\hline & 0.000 & 0.000 & 0.152 \\
\hline \multirow[t]{3}{*}{ Foreign patients (\% list) } & 0.9215 & 0.8487 & 0.8794 \\
\hline & $(0.333)$ & $(0.253)$ & $(0.184)$ \\
\hline & 0.006 & 0.001 & 0.000 \\
\hline \multirow[t]{3}{*}{ Male patients (\% list) } & 2.0358 & 1.2031 & 0.7987 \\
\hline & $(0.502)$ & $(0.471)$ & $(0.302)$ \\
\hline & 0.000 & 0.011 & 0.008 \\
\hline \multirow[t]{3}{*}{ Previous hosp. } & 0.0001 & -0.0003 & -0.0003 \\
\hline & $(0.000)$ & $(0.000)$ & $(0.000)$ \\
\hline & 0.774 & 0.100 & 0.041 \\
\hline \multirow[t]{3}{*}{ Distance } & -0.0254 & -0.0224 & -0.0148 \\
\hline & $(0.002)$ & $(0.002)$ & $(0.002)$ \\
\hline & 0.000 & 0.000 & 0.000 \\
\hline \multirow[t]{3}{*}{ Constant } & -2.3158 & -1.3414 & -0.9957 \\
\hline & $(0.325)$ & $(0.319)$ & $(0.213)$ \\
\hline & 0.000 & 0.000 & 0.000 \\
\hline Ln List_size & offset & offset & offset \\
\hline Area effects & YES & YES & YES \\
\hline Observations & 1,082 & 1,082 & 1,082 \\
\hline Hansen's J chi2(1) & $.0203(p=0.887)$ & $.1439(p=0.704)$ & $3.7363(p=0.053)$ \\
\hline
\end{tabular}

*Standard Error in parenthesis, $p$-value in italics 


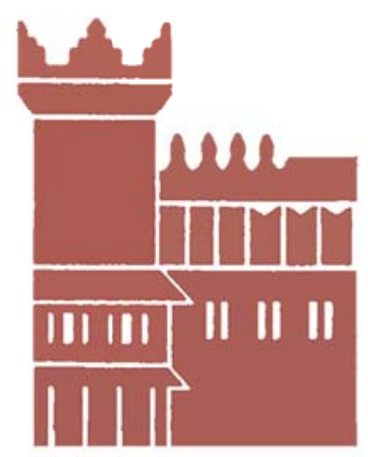

Alma Mater Studiorum - Università di Bologna DEPARTMENT OF ECONOMICS

Strada Maggiore 45

40125 Bologna - Italy

Tel. +39051 2092604

Fax +390512092664

http://www.dse.unibo.it 